\title{
The effect of liquidity on the price discovery process in credit derivatives markets in times of financial distress
}

\author{
Sergio Mayordomo ${ }^{\mathrm{a} *}$, Juan Ignacio Peña ${ }^{\mathrm{b}}$ and Juan Romo ${ }^{\mathrm{c}}$ \\ ${ }^{a}$ Department of Research and Statistics, Comisión Nacional del Mercado de Valores (CNMV), C/ Miguel Ángel 11, \\ 28010 Madrid, Spain; ${ }^{b}$ Department of Business Administration, Universidad Carlos III de Madrid, C/Madrid 126, \\ 28903 Getafe, Madrid, Spain; ${ }^{c}$ Department of Statistics, Universidad Carlos III de Madrid, C/Madrid 126, 28903 \\ Getafe, Madrid, Spain
}

\begin{abstract}
This paper analyses the role of liquidity in the price discovery process. Specifically, we focus on the credit derivatives markets in the context of the subprime crisis. We present a theoretical price discovery model for the asset swap packages (ASPs), bond and credit default swap (CDS) markets and then we test the model with data from 2005 to 2009 on Euro-denominated non-financial firms. Our empirical results show that the ASP market clearly leads the bond market in the price discovery process in all cases, while the leadership between ASPs and CDSs is very sensitive to the appearance of the subprime crisis. Before the crisis, the CDSs market leads the ASP market, but during the crisis, the ASP market leads the CDS market. The liquidity, measured as the relative number of market participants, helps to explain these results.
\end{abstract}

Keywords: price discovery; vector error correction model (VECM); credit derivatives; credit spreads

JEL Classification: C32; C51; G13; G14

\section{Introduction}

The purpose of this paper is to analyse the role of liquidity in the price discovery process. Specifically, we focus on the credit derivatives markets in the context of the subprime crisis. Liquidity is defined in terms of the relative number of participants in a given market, i.e. the number of agents operating in one market relative to the number of participants in another market. Our results suggest that this is the main factor that determines the leadership of the price discovery process between the two markets. We present a theoretical model that helps to understand how the process of price discovery works in the asset swap, bond and credit default swap (CDS) markets. Then we present an empirical application with data from 2005 to 2009 that confirms the theoretical model's insights.

The importance of liquidity in the corporate bond market is not a new topic. Collin-Dufresne, Goldstein, and Martin (2001), Perraudin and Taylor (2003), Elton et al. (2001), Delianedis and Geske (2001) and Chen, Lesmond, and Wei (2007) among others find that liquidity is an additional factor to credit risk which is present in credit spreads. Longstaff, Mithal, and Neis (2005) and Tang and Yan (2007) also support the presence of a liquidity premium in CDS spreads. Tang and Yan (2007) find that both the liquidity level and the liquidity risk ${ }^{1}$ are significant factors in determining CDS spreads. De Jong and Driessen (2006) show that not only liquidity in a given

*Corresponding author. Email: smgomez@cnmv.es 
market affects credit spreads, but there are also liquidity risk and liquidity spillover effects from the treasury bonds and equity markets.

According to Yan and Zivot (2007), an efficient price discovery process is characterized by the fast adjustment of market prices from the old equilibrium to the new equilibrium with the arrival of new information. The new equilibrium is achieved by means of the interactions of buyers and sellers. Thus, the financial instrument price's that contributes more and newer information to the price discovery process should be the one with the highest number of informed market participants. Assuming that in a given market, the higher the overall number of market participants, the higher the number of informed agents and given that the overall number of market participants is a measure of market liquidity, we state that liquidity is the common element in price discovery analyses that determines which market reveals information more efficiently. The price discovery analysis has been applied to a wide number of financial instruments such as stocks, commodities and credit markets among others. Working (1948), Stein (1961) and Garbade and Silver (1983) (GS henceforth) can be considered among the pioneers on this topic. GS posits a formal model to analyse the process of price discovery and show empirically that this process is led by the markets where the number of participants is higher, in their case, the futures market in comparison with the spot market. More recently, a number of analyses that study price discovery on the basis of either Hasbrouck's (1995) or Gonzalo and Granger's (1995) (GG henceforth) methodologies have appeared. Both methodologies are supported by an empirical test based on a vector autoregression (VAR) with an Error Correction Term model. In one of these applications to the commodities market, Figuerola-Ferretti and Gonzalo (2010) (FFG henceforth) develop an econometric approach in order to match the theoretical model of GS (1983) and the econometric methodology of GG based on the permanent-transitory (PT) decomposition. They find that the prices of futures on non-ferrous metals are 'information dominant' with respect to the spot prices in the most liquid futures markets.

The applications of the price discovery methodology to credit derivatives markets are relatively new, if we compare them with the applications to the futures and spot markets, due to the recent development of CDS market. ${ }^{2}$ These applications analyse the efficiency of both CDS and bond markets in terms of price discovery. Blanco, Brennan, and Marsh (2005) and Zhu (2006) use American and European corporate bonds and CDSs and obtain that the CDS market reflects the information more accurately and quickly than the bond market. The same results are found in Baba and Inada (2007) who repeat the same analysis for subordinated CDS and subordinated bond spreads of Japanese mega-banks. In other analyses of price discovery based on emerging markets sovereign bonds and CDS, Ammer and Cai (2007) find that bond spreads lead CDS premiums more often than has been found for investment-grade corporate credits. ${ }^{3}$ Based on iTraxx companies, Dötz (2007) finds that both markets make net contributions to price discovery, with the CDS market dominating slightly over the bond market. ${ }^{4}$ In general terms, liquidity and credit risk factors are considered as the main determinants of the role of leadership in credit markets.

The analysis of price discovery is extended in Norden and Weber (2004), Forte and Peña (2009) and Coudert and Gex (2010) to the stock market. All of them find that the stock market leads the CDS and bond markets, while there is a leading role of the CDS market with respect to the bond market. $^{5}$

However, a formal theoretical model that analyses the process of price discovery in credit derivatives markets is still lacking. We fill this gap presenting a theoretical model based on the participation of different market players and match this model with GG's econometric methodology by means of FFG's econometric approach. Our model is an extension of the GS model allowing for the simultaneous participation of agents in different markets. This is our first contribution. 
Moreover, we find another gap in the price discovery literature in credit markets, namely, no analysis of the price discovery process between ASPs and CDSs has been carried out up to now. ${ }^{6}$ Price discovery in credit markets has focused on bond and CDS spreads. We analyse the price discovery process between ASPs and CDSs in the time period from 2005 to 2009 and find that the leadership, in terms of price discovery, between ASPs and CDSs is very sensitive to the appearance of the subprime crisis. During the period before the crisis, the CDSs appear clearly as the more efficient market in $87.5 \%$ of the cases. During the crisis, ASP spreads reveal more efficiently credit risk than before up to the point that in $71.88 \%$ of the cases ASP spreads lead CDS spreads in the price discovery process. This is our second contribution.

De Wit (2006), Felsenheimer (2004) and Francis, Kakodkar, and Martin (2003) among others suggest that ASP spreads should be a more accurate measure of credit risk than bond spreads. Actually, according to Schonbucher (2003), ASPs are liquid instruments and it is even easier to trade an ASP than the underlying defaultable bond alone. We give support to this idea by means of our empirical price discovery analysis for asset swap and bond spreads up to the point that according to GS (1983) terms, we find that the bond market is a 'pure satellite' of the asset swap market. This finding is our third contribution.

To summarize, our analysis and results are significant contributions to an important contemporary issue in the discipline of Financial Institutions and Markets research for the following reasons. First, we present a simple theoretical model which helps to understand the process of price discovery in credit derivatives markets in the context of the recent financial crisis. Second, our empirical results may be of special interest for market regulators and investors because they provide a number of insights into the relative reliability of market-based credit risk measures. Given the fact of the relatively low liquidity of CDS market in comparison with bonds and ASPs, our results cast doubts on the representativeness of market prices quoted in the CDS market in periods of financial distress as the current crisis. The key implication of this result is that inferences on the creditworthiness of a given firm based solely in CDS spreads during periods of high market turbulence and low liquidity are bound to be misleading. Third, given that we find that, in all cases, the ASP spread reflects credit risk more efficiently than the bond spread, our results suggest that it is more appropriate to use the ASP spread as a credit risk indicator instead of the bond spread.

This paper is divided into four sections, in Section 2 we describe the price discovery model and the hypotheses to test. Section 3 describes the data. Section 4 presents the price discovery results. Section 5 concludes.

\section{Price discovery model}

First of all, we report a brief definition of the two credit derivatives employed in this paper. A CDS is a traded insurance contract which provides protection against credit risk until the occurrence of a credit event or the maturity date of the contract, whichever is first, in exchange for periodic premium payments (the CDS premium or CDS spread) and/or an upfront payment. In the event of default, CDSs are settled in one of two ways: by physical settlement or by cash settlement. A buyer of CDS protection on a single name makes regular payments of the CDS' full running spread to the protection seller. The CDS contract that we analyse is unfunded and so investors do not make an up-front payment (ignoring dealer margins and transaction costs). Thus, the traded CDS premium or the market CDS spread is an at-market annuity premium rate $\bar{s}$ such that the market value of the CDS is zero at origination.

An ASP contains a defaultable coupon bond with coupon $\bar{c}$ and an interest-rate swap (IRS) that swaps the bond's coupon (fixed leg) into Euribor plus the asset swap spread rate $s^{A}$ (floating leg). 
The asset swap's fixed leg represents the buyer's periodic fixed rate payments, while its floating leg represents the seller's payment. The asset swap spread is chosen so that the value of the whole package is the par value of the defaultable bond and for this reason it is also known as a par to par swap. The interest rate swap (IRS) included in the asset-swap package has zero cost and so the asset swap's cost is equal to the price of the defaultable bond included in the package. As the asset swap spread valuation is obtained using the bond's face value (FV), an up-front payment must be added to the bond's price at the investment period $t$ to ensure that the value of the whole package is FV. The asset swap spread is computed by setting the present value of all cash flows equal to zero and the up-front payment represents the net present value of the swap.

The goal of the price discovery model is to analyse the dynamics and interaction between CDS and ASP spreads in an equilibrium non-arbitrage model. ${ }^{7}$ The procedure is based on the behaviour of market participants in the corresponding market place. We adapt and extend to the credit derivatives markets, the model of price discovery developed by GS and focuses on the case where the arbitrageurs present a finite elasticity demand/supply of arbitrage services. We modify the model of the price discovery developed by GS by considering five different types of market participants instead of three. Each agent who participates in the market place can be classified into one of the following groups:

(i) The first group is formed by arbitrageurs. Whenever there exists an adequate grade of liquidity, they try to exploit possible discrepancies among CDS and ASP prices. Thus, they invest whenever a security is trading above/below the 'correct price'. ${ }^{8}$

(ii) Agents that only take positions in the asset swap market. They can be understood either as long-run investors such as portfolio managers who feel attracted by asset swap characteristics or as investors who must hold any capital requirement. Examples of these agents are insurance firms or pension funds that invest in bonds or asset swaps as a 'buy and hold' strategy.

(iii) Agents that only participate in the CDS market either as protection sellers or buyers. For instance, the collateralized debt obligation (CDO) issuer usually enters the CDS market as a protection seller. ${ }^{9}$ These participants in the CDS market can also be understood in most cases as speculators. ${ }^{10}$ Some examples of these agents are hedge funds that benefit from CDS leverage effect, contrary to the ASPs or bonds, whose buyers incur an outlay at the investment date.

(iv) Agents that participate in both financial markets as market makers. According to Acharya, Schaefer, and Zhang (2007), most of the financial institutions that make markets in corporate bonds are also the liquidity providers in other related segments of the fixed-income markets, specifically in credit markets such as CDSs and CLOs or CDOs. This type of agents can also be considered as financial intermediaries who manage portfolios for different customers or simply as investors in credit markets. We consider that these individuals take a given position in one market or the other, attending to their reservation prices for the corresponding market.

(v) Agents that use the CDS market to hedge their positions in corporate debt. These agents buy bonds or asset swaps that at the same time are hedged by means of e CDSs. ${ }^{11}$ They employ CDSs to hedge their bond or ASP positions contrary to the individuals in group (iii) who do not have any underlying bond or ASP.

GS, as well as FFG, consider three types of agents and two markets in such a way that the only individuals who operate in both markets are the arbitrageurs. We offer a more general model that includes participants who operate in both markets and hedgers. It means that both markets are not only linked by arbitrageurs as in GS but by the two additional groups of individuals. This aspect 
is of special relevance for understanding price discovery in credit markets, given that price setters in the CDS market are frequently the same as in bonds or asset swap markets and the link is not only given by the arbitrageurs.

\subsection{Arbitrageur's demand}

The procedure employed by arbitrageurs to exploit potential mispricings between the CDS and the ASP is based on a cash-and-carry strategy. The arbitrageur strategy is constructed from the following portfolios depending on if asset swap spread is above (below) the CDS spread:

\section{Portfolio I}

- Long (short) position in a CDS with an annual full running premium equal to $\bar{s}_{t}$ which is paid (received) quarterly.

\section{Portfolio II}

- Long (short) position in an ASP whose cost is equal to the bond's par value. The investor pays to (receives from) the counterparty, the bond's coupon at the coupon dates in exchange for receiving (paying) every quarter the 3-month Euribor rate $\left(E_{3 m, t}\right)$ plus the asset swap spread $\left(s_{t}^{A}\right)$. The quarterly payment dates coincide with the CDS premium payment dates. ${ }^{12}$

- Loan (deposit) with a principal equal to the bond's FA at 3-month Euribor. ${ }^{13}$ Interest payment dates coincide with both the CDS premium and the asset swap floating leg payment dates.

Portfolio II is equivalent to a synthetic short (long) position in a CDS and so, there should be an equivalence relationship between CDS and asset swap spreads. Otherwise, arbitrage opportunities may appear. ${ }^{14}$

At origination, the cost of both portfolios is zero, and so the net payoff is also zero. A quarter after origination and every subsequent quarter, in case of no default, a combination of long positions on both the CDS and ASP leads to a net payment for the investor equal to the difference between ASP and CDS spreads, $s_{t}^{A}-\bar{s}_{t},{ }^{15}$ both of them converted into quarterly terms using an 'actual/360' day count convention. ${ }^{16}$ This difference is known as the basis.

However, in case of default, the investor's net payment differs from the basis. On the one hand, the IRS included into the ASP remains alive after default, and it should be serviced or unwound at market value. On the other hand, the CDS accrued premium as well as loan's accrued interests must be paid. Moreover, not only the underlying bond but a given number of bonds, even cheaper than the underlying, can be delivered which gives the holder of a CDS a cheapest-to-deliver (CTD) bond option. Then, the net payment is different from the basis.

In order to find the non-arbitrage equilibrium condition, the following assumptions must be imposed:

A1. No limitations on short sales of the ASP. ${ }^{17}$

A2. No limitations on borrowing and no restrictions on participating in the ASPs and CDSs market (market segmentation does not affect the arbitrageur).

A3. No tax effects.

A4. No additional costs except the ones required to fund an ASP position. 
Arbitrageurs can be identified as hedge fund investors whose demand takes place after identifying securities that are trading above/below the correct price. Among the strategies employed to exploit arbitrage opportunities in fixed-income markets hedge funds employ merger arbitrage, fixedincome arbitrage, capital structure arbitrage, volatility arbitrage or what is known, from our point of view erroneously, as statistical arbitrage that is based on the cointegration methodology proposed by Engle and Granger (1987). ${ }^{18}$ Of the above strategies, the one employed to exploit transitory mispricings in CDS and ASP spreads is the one based on the cointegration methodology. The idea is that, given two cointegrated assets, an investor can profit by buying one cointegrated asset and selling the other in case of transitory mispricings. The investor is betting that the spread between the two cointegrated assets will narrow, given the cointegration's adjustment process towards an economic equilibrium. Thus, if the ASP spread is too high relative to the long-term equilibrium, arbitrageurs will take long positions both in CDSs and ASPs. This long-term noarbitrage equilibrium condition is also known as the equivalence or parity relationship between ASP and CDS spreads. Thus, we define the arbitrageurs demand on the basis of the following long-run equivalence relationship:

$$
s_{t}^{A}=\beta_{2} \bar{s}_{t}+\beta_{3} .
$$

According to Blanco, Brennan, and Marsh's (2005) terminology, $\beta_{2}$ includes non-transient factors besides credit risk. ${ }^{19}$ The parameter $\beta_{3}$ includes factors or imperfections that generate a constant difference between both spreads such as institutional factors causing differences in funding or transaction costs, or other costs in general.

The demand of arbitrageurs will depend on the grade to which the equivalence relationship holds and on their elasticity of demand which is denoted as $H$ :

$$
H\left(\beta_{2} \bar{s}_{t}+\beta_{3}-s_{t}^{A}\right), \quad H>0 .
$$

We assume that there exist an unspecified number of arbitrageurs and $\beta_{2}$ is allowed to be different from $1 .{ }^{20}$ The possibility of a default means that the cash-and-carry strategy, which is based on long positions in the CDS and short positions in the synthetic CDS or vice versa, is not completely riskless. In case of default, the investor's net payment differs from the basis and the arbitrageur could even incur losses, which means that the strategy is not exempt of risk. Another argument that reinforces the idea that the strategy is not riskless is that the CDS and the synthetic CDS are not exactly the same asset and thus their prices can change in a different way at a given time period. Moreover, although we assume that there are no restrictions on corporate bond and ASP short sales, these may appear in real world. ${ }^{21}$ These restrictions make it difficult to exploit arbitrage opportunities whenever short sales are needed and this fact limits the arbitrageurs demand. Moreover, there could be constraints in the short-run availability of arbitrage capital or restrictions to market participation. For this reason, it seems more realistic to assume that $H$ is finite. GS also consider as more realistic a finite value for $H$ in the commodities markets.

\subsection{Demand schedule of market participants}

The behaviour of the other agents in the market place is defined according to their demand schedules. Thus, the demand schedule for the $j$ th participant who deals only in ASP market is

$$
E_{j, t}-A^{\mathrm{ASP}}\left(R_{j, t}^{\mathrm{ASP}}-s_{t}^{A}\right), \quad A^{\mathrm{ASP}}>0, \quad j=1, \ldots, N_{\mathrm{ASP}},
$$

where according to the GS notation we define $E_{j, t}$ as the ASP endowment of the $j$ th participant immediately prior to period $t, N_{\mathrm{ASP}}$ is the number of participants who deal only in the asset 
swap market. Let $R_{j, t}^{\mathrm{ASP}}$ be the reservation price at which participant $j$ th is willing to hold the endowments of ASPs $E_{j, t}$ while $A^{\mathrm{ASP}}$ represents the elasticity of demand which is assumed to be the same for the total $N_{\mathrm{ASP}}$ participants. Let $A^{\mathrm{ASP}}\left(R_{j, t}^{\mathrm{ASP}}-s_{t}^{A}\right)$ be the variation in the endowments prior to period $t$. An increase in the asset swap spread implies an increase in the ASP buyers' returns given that they are equal to the sum of the floating rate and the asset swap spread. Therefore, there is an increase in the ASP endowments prior to period $t+1, E_{j, t+1}$, whenever $R_{j, t}^{\mathrm{ASP}}<s_{t}^{A}$. Notice that it is his reservation price with respect to the ASP spread what defines an investor as an ASP seller or buyer.

The demand schedule for the participants who deal only in the CDS market is as follows:

$$
E_{i, t}-A^{\mathrm{CDS}}\left(\bar{s}_{t}-R_{i, t}^{\mathrm{CDS}}\right), \quad A^{\mathrm{CDS}}>0, \quad i=1, \ldots, N_{\mathrm{CDS}},
$$

where $E_{i, t}$ is the CDS endowment of the $i$ th participant immediately prior to period $t, N_{\mathrm{CDS}}$ is the number of participants who deal only in the CDS market, $R_{i, t}^{\mathrm{CDS}}$ is the reservation price at which participant $i$ th is willing to hold the endowments of CDSs $E_{i, t}$ while $A^{\mathrm{CDS}}$ represents the elasticity of demand which is the same for the total number of participants $N_{\mathrm{CDS}}$. The individuals operating only in the CDS market are buyers or sellers depending on their reservation prices. These agents can be considered as speculators that bet on the probability of default. The individuals with $\bar{s}_{t}>R_{i, t}^{\mathrm{CDS}}$ will be net suppliers of CDSs or protection sellers. They benefit from the periodic payments that receive and are willing to provide default protection at this price. ${ }^{22}$ As $\bar{s}_{t}>R_{i, t}^{\mathrm{CDS}}$, the CDS endowments of these individuals decrease with respect to those immediately prior to period t. This supply of CDSs could be absorbed by an individual $i_{2}^{\text {th }}$ with a reservation price such that $\bar{s}_{t}<R_{i_{2}, t}^{\mathrm{CDS}}$ or by the debt hedgers or by the other individuals that participate in both markets at the same time. The individuals with $\bar{s}_{t}<R_{i_{2}, t}^{\mathrm{CDS}}$ are net buyers of CDSs or net default protection buyers.

The demand schedule of individuals who participate in both financial markets as market makers is defined from the reservation price in the corresponding market such that the endowments of ASPs are not conditioned by the endowments of CDSs. The ASPs and CDSs' demand schedule of these agents is as follows:

$$
\begin{array}{ll}
E_{k, t}^{B, \mathrm{ASP}}-A^{B, \mathrm{ASP}}\left(R_{k, t}^{B, \mathrm{ASP}}-s_{t}^{A}\right), & A^{B, \mathrm{ASP}}>0, \quad k=1, \ldots, N_{\mathrm{BOTH}} \\
E_{k, t}^{B, \mathrm{CDS}}-A^{B, \mathrm{CDS}}\left(\bar{s}_{t}-R_{k, t}^{B, \mathrm{CDS}}\right), & A^{B, \mathrm{CDS}}>0, \quad k=1, \ldots, N_{\mathrm{BOTH}},
\end{array}
$$

where the notation in Equations (5) and (6) is equivalent to the one employed in Equations (3) and (4).

The demand schedule of hedgers is conditioned by their positions in ASPs. We assume that the positions in ASPs of these agents are completely hedged. Thus, the endowments and demand of CDSs are independent of the CDSs premium and they are equal to the endowments and demand of ASPs. The endowments of ASPs increase as the ASP spread increases:

$$
E_{h, t}^{H, \mathrm{ASP}}-A^{H, \mathrm{ASP}}\left(R_{h, t}^{H, \mathrm{ASP}}-s_{t}^{A}\right), \quad A^{H, \mathrm{ASP}}>0, \quad h=1, \ldots, N_{H} .
$$

Notation for Equation (7) is equivalent to the one in Equations (3) and (5) and it represents the debt hedgers demand schedule for both ASPs and CDSs.

\subsection{Clearing market conditions}

Using all the above demand schedules for the five types of individuals, we set the clearing market conditions for both markets. ${ }^{23}$ 
The ASP market will clear at the value of $s_{t}^{A}$ that solves the supply/demand equation:

$$
\begin{aligned}
\sum_{j=1}^{N_{\mathrm{ASP}}} & E_{j, t}+\sum_{k=1}^{N_{\mathrm{BOTH}}} E_{k, t}^{B, \mathrm{ASP}}+\sum_{h=1}^{N_{H}} E_{h, t}^{H, \mathrm{ASP}} \\
= & \sum_{j=1}^{N_{\mathrm{ASP}}}\left[E_{j, t}-A^{\mathrm{ASP}}\left(R_{j, t}^{\mathrm{ASP}}-s_{t}^{A}\right)\right]+\sum_{k=1}^{N_{\mathrm{BOTH}}}\left[E_{k, t}^{B, \mathrm{ASP}}-A^{B, \mathrm{ASP}}\left(R_{k, t}^{B, \mathrm{ASP}}-s_{t}^{A}\right)\right] \\
& +\sum_{h=1}^{N_{H}}\left[E_{h, t}^{H, \mathrm{ASP}}-A^{H, \mathrm{ASP}}\left(R_{h, t}^{H, \mathrm{ASP}}-s_{t}^{A}\right)\right]-H\left(\beta_{2} \bar{s}_{t}+\beta_{3}-s_{t}^{A}\right) .
\end{aligned}
$$

The CDS market will clear at the value of $\bar{s}_{t}$ that solves the supply/demand equation:

$$
\begin{aligned}
& \sum_{i=1}^{N_{\mathrm{CDS}}} E_{i, t}+\sum_{k=1}^{N_{\mathrm{BOTH}}} E_{k, t}^{B, \mathrm{CDS}}+\sum_{h=1}^{N_{H}} E_{h, t}^{H, \mathrm{ASP}} \\
& \quad=\sum_{i=1}^{N_{\mathrm{CDS}}}\left[E_{i, t}-A^{\mathrm{CDS}}\left(\bar{s}_{t}-R_{i, t}^{\mathrm{CDS}}\right)\right]+\sum_{k=1}^{N_{\mathrm{BOTH}}}\left[E_{k, t}^{B, \mathrm{CDS}}-A^{B, \mathrm{CDS}}\left(\bar{s}_{t}-R_{k, t}^{B, \mathrm{CDS}}\right)\right] \\
& \quad+\sum_{h=1}^{N_{H}}\left[E_{h, t}^{H, \mathrm{ASP}}-A^{H, \mathrm{ASP}}\left(R_{h, t}^{H, \mathrm{ASP}}-s_{t}^{A}\right)\right]-H\left(\beta_{2} \bar{s}_{t}+\beta_{3}-s_{t}^{A}\right) .
\end{aligned}
$$

We solve the previous equations in order to find the CDS and ASP prices that clear both markets. For this purpose and as in GS, we assume that the mean reservation price for the $N_{\mathrm{CDS}}$ individuals in the CDS market is $R_{t}^{\mathrm{CDS}}=N_{\mathrm{CDS}}^{-1} \sum_{i=1}^{N_{\mathrm{CDS}}} R_{i, t}^{\mathrm{CDS}}$ and for the $N_{\mathrm{ASP}}$ individuals in the ASP market, it is given by $R_{t}^{\mathrm{ASP}}=N_{\mathrm{ASP}}^{-1} \sum_{j=1}^{N_{\mathrm{ASP}}} R_{j, t}^{\mathrm{ASP}}$. For the individuals who are present in both markets, we have that the mean reservation prices are $R_{t}^{B, \mathrm{CDS}}=N_{\mathrm{BOTH}}^{-1} \sum_{k=1}^{N_{\text {BОтн }}} R_{k, t}^{B, \mathrm{CDS}}$ and $R_{t}^{B, \mathrm{ASP}}=N_{\mathrm{BOTH}}^{-1} \sum_{k=1}^{N_{\mathrm{BOTH}}} R_{k, t}^{B, \mathrm{ASP}}$, as well as for the hedgers, the reservation price is defined as $R_{t}^{H, \mathrm{ASP}}=N_{H}^{-1} \sum_{h=1}^{N_{H}} R_{h, t}^{H, \mathrm{ASP}}$. As in GS, we assume that the elasticities are the same for all market participants in ASP and CDS markets $\left(A^{\mathrm{ASP}}=A^{B, \mathrm{ASP}}=A^{\mathrm{CDS}}=A^{B, \mathrm{CDS}}=A^{H, \mathrm{ASP}}\right){ }^{24}$ Solving Equations (8) and (9) for $s_{t}^{A}$ and $\bar{s}_{t}$ as a function of the mean reservation prices, we obtain: ${ }^{25}$

$$
\begin{aligned}
& s_{t}^{A}= \frac{C+H \beta_{2} F+A\left(N_{\mathrm{CDS}}+N_{\mathrm{BOTH}}\right)\left(N_{H} R_{t}^{H, \mathrm{ASP}}+N_{\mathrm{BOTH}} R_{t}^{B, \mathrm{ASP}}+N_{\mathrm{ASP}} R_{t}^{\mathrm{ASP}}\right)}{B}, \\
& \begin{array}{c}
-D+H F+A\left\{\left(N_{\mathrm{CDS}}\left(N_{H}+N_{\mathrm{BOTH}}+N_{\mathrm{ASP}}\right) R_{t}^{\mathrm{CDS}}\right.\right. \\
\bar{s}_{t}=
\end{array} \\
&+N_{H}\left[N_{\mathrm{BOTH}}\left(-R_{t}^{H, \mathrm{ASP}}+R_{t}^{B, \mathrm{ASP}}+R_{t}^{B, \mathrm{CDS}}\right)+N_{\mathrm{ASP}}\left(-R_{t}^{H, \mathrm{ASP}}+R_{t}^{\mathrm{ASP}}\right)\right] \\
&\left.+N_{\mathrm{BOTH}}\left(N_{\mathrm{BOTH}}+N_{\mathrm{ASP}}\right) R_{t}^{B, \mathrm{CDS}}\right\}
\end{aligned}
$$

where the grouped elements that appear in Equations (10) and (11) are defined as follows:

$$
\begin{aligned}
B= & A\left(N_{\mathrm{CDS}}+N_{\mathrm{BOTH}}\right)\left(N_{H}+N_{\mathrm{BOTH}}+N_{\mathrm{ASP}}\right) \\
& +H\left(N_{\mathrm{CDS}}+N_{\text {BOTH }}+\beta_{2} N_{\mathrm{BOTH}}+\beta_{2} N_{\mathrm{ASP}}\right)
\end{aligned}
$$




$$
\begin{aligned}
& C=H \beta_{3}\left(N_{\mathrm{CDS}}+N_{\mathrm{BOTH}}\right) \\
& D=H \beta_{3}\left(N_{\mathrm{ASP}}+N_{\mathrm{BOTH}}\right) \\
& F=N_{\mathrm{CDS}} R_{t}^{\mathrm{CDS}}+N_{\mathrm{BOTH}}\left(R_{t}^{B, \mathrm{ASP}}+R_{t}^{B, \mathrm{CDS}}\right)+N_{\mathrm{ASP}} R_{t}^{\mathrm{ASP}} .
\end{aligned}
$$

In order to derive the dynamic price relationship, the model in Equations (10) and (11) must be characterized with a description of the evolution of the reservation prices. Immediately after the market clearing in period $t-1$, a given market participant in CDSs is willing to hold an amount $E_{i, t}$ or $E_{k, t}^{B, \mathrm{CDS}}$, depending on the investor's type, at price $\bar{s}_{t-1}$. A given participant in the ASP market is willing to hold an amount $E_{j, t}, E_{k, t}^{B, \mathrm{ASP}}$ or $E_{h, t}^{H, \mathrm{ASP}}$, depending on the investor's type, at price $s_{t-1}^{A}$. It implies that the corresponding reservation prices after that clearing are $\bar{s}_{t-1}$ and $s_{t-1}^{A}$ for participants in CDS and ASP markets, respectively. Thus, the reservation prices behave according to the following process:

$$
\begin{array}{cl}
R_{i, t}^{\mathrm{CDS}} & =\bar{s}_{t-1}+v_{t}+w_{i, t}^{\mathrm{CDS}}, \quad i=1, \ldots, N_{\mathrm{CDS}} \\
R_{j, t}^{\mathrm{ASP}} & =s_{t-1}^{A}+v_{t}+w_{j, t}^{\mathrm{ASP}}, \quad j=1, \ldots, N_{\mathrm{ASP}} \\
R_{k, t}^{B, \mathrm{CDS}} & =\bar{s}_{t-1}+v_{t}+w_{k, t}^{B, \mathrm{CDS}}, \quad k=1, \ldots, N_{\mathrm{BOTH}} \\
R_{k, t}^{B, \mathrm{ASP}} & =s_{t-1}^{A}+v_{t}+w_{k, t}^{B, \mathrm{ASP}}, \quad k=1, \ldots, N_{\mathrm{BOTH}} \\
R_{h, t}^{H, \mathrm{ASP}} & =s_{t-1}^{A}+v_{t}+w_{h, t}^{H, \mathrm{ASP}}, \quad h=1, \ldots, N_{H}
\end{array}
$$

such that:

$$
\begin{aligned}
\operatorname{cov}\left(v_{t}, w_{l, t}\right) & =0, \quad \forall l \\
\operatorname{cov}\left(w_{e, t}, w_{l, t}\right) & =0, \quad \forall l \neq e,
\end{aligned}
$$

where $v_{t}$ is a white noise with finite variance that is a common component for all participants and $w_{i, t}, w_{j, t}, w_{k, t}$ and $w_{h, t}$ are also white noises with finite variance that represent the idiosyncratic component for participants $i, j, k$ and $h$, respectively.

As GS states, the price change for the above individuals, for instance $R_{i, t}^{\mathrm{CDS}}-\bar{s}_{t-1}$ for the individuals who operate only in the CDS market, reflects the arrival of new information between period $t-1$ and period $t$ which changes the price at which the $i$ th participant is willing to hold the quantity $E_{i, t}$ of the CDS. The price changes have a component common to all participants $\left(v_{t}\right)$ and a component idiosyncratic to the $i$ th participant $\left(w_{i, t}\right)$. Thus, the mean reservation price can be also expressed as follows:

$$
\begin{gathered}
R_{t}^{\mathrm{CDS}}=\bar{s}_{t-1}+v_{t}+w_{t}^{\mathrm{CDS}} \\
R_{t}^{\mathrm{ASP}}=s_{t-1}^{A}+v_{t}+w_{t}^{\mathrm{ASP}} \\
R_{t}^{B, \mathrm{CDS}}=\bar{s}_{t-1}+v_{t}+w_{t}^{B, \mathrm{CDS}} \\
R_{t}^{B, \mathrm{ASP}}=s_{t-1}^{A}+v_{t}+w_{t}^{B, \mathrm{ASP}} \\
R_{t}^{H, \mathrm{ASP}}=s_{t-1}^{A}+v_{t}+w_{t}^{H, \mathrm{ASP}},
\end{gathered}
$$


where $w_{t}^{\mathrm{CDS}}=N_{\mathrm{CDS}}^{-1} \sum_{i=1}^{N_{\mathrm{CDS}}} w_{i, t}^{\mathrm{CDS}}, w_{t}^{\mathrm{ASP}}=N_{\mathrm{ASP}}^{-1} \sum_{j=1}^{N_{\mathrm{ASP}}} w_{j, t}^{\mathrm{ASP}}, w_{t}^{B, \mathrm{CDS}}=N_{\mathrm{BOTH}}^{-1} \sum_{k=1}^{N_{\text {BOTH }}} w_{k, t}^{B, \mathrm{CDS}}$, $w_{t}^{B, \mathrm{ASP}}=N_{\mathrm{BOTH}}^{-1} \sum_{k=1}^{N_{\text {ВОтн }}} w_{k, t}^{B, \mathrm{ASP}}$ and $w_{t}^{H, \mathrm{ASP}}=N_{H}^{-1} \sum_{h=1}^{N_{H}} w_{h, t}^{H, \mathrm{ASP}}$. We substitute the expressions (14) into the Equations (10) and (11) and obtain the following equation (see Appendix 1):

$$
\left(\begin{array}{c}
\Delta s_{t}^{A} \\
\Delta \bar{s}_{t}
\end{array}\right)=\frac{H}{B}\left[\begin{array}{c}
-\left(N_{\mathrm{BOTH}}+N_{\mathrm{CDS}}\right) \\
\left(N_{\mathrm{BOTH}}+N_{\mathrm{ASP}}\right)
\end{array}\right]\left(1,-\beta_{2},-\beta_{3}\right)\left(\begin{array}{c}
s_{t-1}^{A} \\
\bar{s}_{t-1} \\
1
\end{array}\right)+\left(\begin{array}{c}
u_{t}^{\mathrm{ASP}} \\
u_{t}^{\mathrm{CDS}}
\end{array}\right),
$$

where $\left(u_{t}^{\mathrm{ASP}}, u_{t}^{\mathrm{CDS}}\right)$ is a vector white noise with $E\left(u_{t}\right)=0$ and $\operatorname{Var}\left(u_{t}\right)=\Omega>0$. In $u_{t}$, we include both the common components and the participants' noises. ${ }^{26}$ The model in Equation (15) can be changed into a vector error correction model (VECM) model by the subtracting vector of prices $\left(s_{t}^{A}, \bar{s}_{t}\right)^{\prime}$ from both sides.

Although GS provides the first step for understanding price discovery, current analyses are based on either Hasbrouck's (1995) or Gonzalo and Granger's (1995) methodologies. Contrary to GS, the last two approaches are based on a VAR with an Error Correction Term model. As in FFG, we pretend to match the GS and GG methodology from the use of a VECM specification. Equation (15) can be extended, with lags of vector $\left(\Delta s_{t}^{A}, \Delta \bar{s}_{t}\right)^{\prime}$, and represented according to a VECM specification:

$$
\Delta X_{t}=\alpha \beta^{\prime} X_{t-1}+\sum_{i=1}^{p} \Gamma_{i} X_{t-i}+u_{t}
$$

where $X_{t}=\left(s_{t}^{A}, \bar{s}_{t}\right)^{\prime}$ and $u_{t}$ is a white noise vector. According to expression (15),

$$
\alpha^{\prime}=\left(-\frac{H}{B}\left(N_{\mathrm{BOTH}}+N_{\mathrm{CDS}}\right), \frac{H}{B}\left(N_{\mathrm{BOTH}}+N_{\mathrm{ASP}}\right)\right) \text { and } \beta^{\prime}=\left(1,-\beta_{2}\right) .
$$

In this paper, we adopt GG's methodology and thus, their PT component decomposition to measure market contribution to price discovery (see Appendix 2). We find that the percentages of price discovery of ASP and CDS markets can be defined from the GG price discovery metrics that we denote as $\mathrm{GG}_{1}$ and $\mathrm{GG}_{2}$, respectively:

$$
\mathrm{GG}_{1}=\frac{\alpha_{2}}{-\alpha_{1}+\alpha_{2}} \text { and } \mathrm{GG}_{2}=\frac{-\alpha_{1}}{-\alpha_{1}+\alpha_{2}}
$$

Or equivalently:

$$
\mathrm{GG}_{1}=\frac{N_{\mathrm{BOTH}}+N_{\mathrm{ASP}}}{2 N_{\mathrm{BOTH}}+N_{\mathrm{ASP}}+N_{\mathrm{CDS}}} \quad \text { and } \quad \mathrm{GG}_{2}=\frac{N_{\mathrm{BOTH}}+N_{\mathrm{CDS}}}{2 N_{\mathrm{BOTH}}+N_{\mathrm{ASP}}+N_{\mathrm{CDS}}} .
$$

Note that the number of hedgers are not relevant to define the price discovery metrics and as a consequence in the price discovery process. ${ }^{27}$ Note also that although the theoretical model's liquidity variable is defined as the number of market participants in a given market relative to other market, this metric can be easily related with other commonly employed liquidity measures like the number of contracts or the volume in a given market relative to the other.

\subsection{Hypotheses}

According to the price discovery metric in Equation (18), the interaction between both markets due to the market players that operate jointly in CDS and ASP markets is of crucial importance. 
Panel A: CDS amount outstanding and bond trading (in USD trillion)

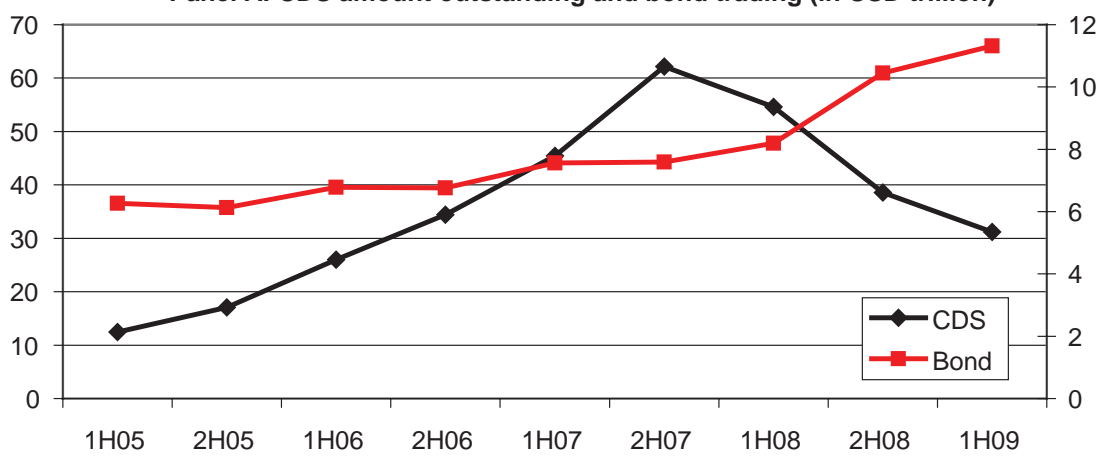

Panel B: Ratio of bond trading and CDS amount outstanding (in percentage)

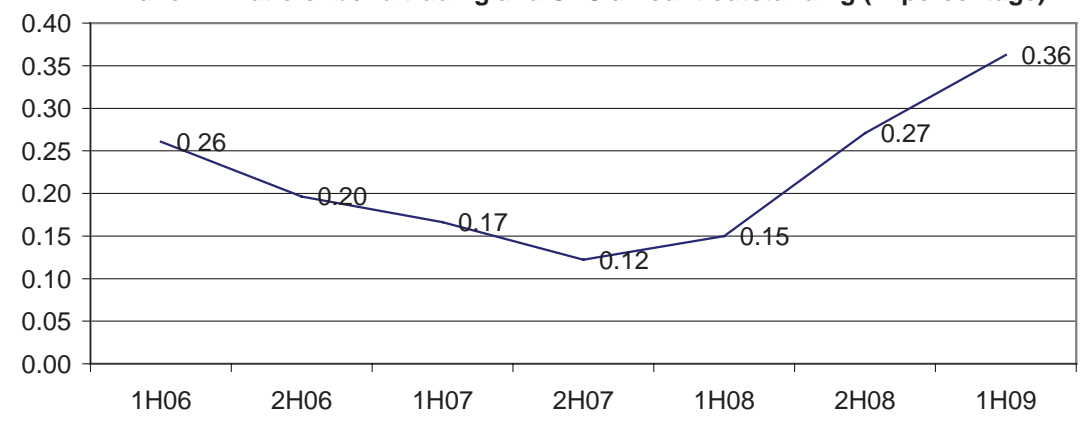

Figure 1. Credit default swap notional amount outstanding and bond trading on exchanges.

Source: CDS Notional Amount Outstanding: International Swaps and Derivatives Association (ISDA) Bond Trading on Exchanges: World Federation of Exchanges.

The subprime crisis has affected liquidity in credit derivatives markets and as a consequence the five types of market players. The subprime crisis leads to a decrease in CDS liquidity. The high counterparty risk in the CDS market jointly with, as Dötz (2007) suggests, the relatively high concentration and the homogeneousness of its often leveraged market players has affected the CDS market severely. According to the International Financial Services London (IFSL) Research (2009a), centralized clearing and voluntary termination of contacts have contributed to a 39\% drop in notional amounts outstanding of CDS from \$62 trillion at end-2007 to \$38 trillion at end-2008, according to the International Swaps and Derivatives Association (ISDA) (see Panel A of Figure 1). ${ }^{28}$ However, as the IFSL Research (2009b) states, the fall in liquidity during the subprime crisis has increased the importance of bond markets as a source of finance for companies and governments. The issuance of corporate bonds increased to record levels towards the end of 2008 and the first quarter of 2009, particularly in Europe. ${ }^{29}$ With respect to the bond trading activity, IFSL Research (2009b) reports that the trading of bonds on exchanges increased by a quarter in 2008 to over $19 \$$ trillion (see Panel A of Figure 1).

Our first aim is to analyse whether in periods when liquidity is especially low, CDSs maintain their role as the main determinant in the price discovery process. To test this statement, we analyse price discovery for two subperiods which correspond to the periods before and after the subprime crisis such that the break-point is set at July 2007. Given previous published evidence, ${ }^{30}$ we expect that before the crisis, CDSs lead the price discovery process or at least, if the role of participants in 


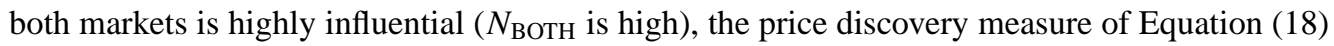
should be close to $0.5 .^{31}$ According to our model, the leadership of the CDS market can be explained by its higher liquidity (number of participants). The buy-and-hold strategy employed by the ASP or bond investors contrary to the active behaviour of CDS investors, in part due to the leverage associated with a CDSs purchase, could lead to a higher market activity in the CDS market than in the bond market before the subprime crisis.

Hypothesis 1: Under scenarios with high liquidity such as before the subprime crisis, the CDS market should lead the ASP market in the price discovery process.

The reason is that the number of participants (liquidity) in the CDS market is high relative to the number of players in the ASP market $\left(N_{\mathrm{CDS}}>N_{\mathrm{ASP}}\right)$. In addition to the previous hypothesis, when the number of individuals who operate in both markets is high ( $N_{\mathrm{BOTH}}$ is high), the CDS market should reveal information as efficiently as the ASP market.

According to Acharya and Schaefer (2006) and Acharya, Schaefer, and Zhang (2007), in periods with low liquidity one should expect that market makers, who at the same time are price setters in both credit markets, are financially constrained and thus their participation in both markets will decrease. In terms of our model, notation is equivalent to say that $N_{\text {BOTH }} \rightarrow 0$ and the new percentages of price discovery would change into a measure similar to the one introduced by GS:

$$
\frac{N_{\mathrm{ASP}}}{N_{\mathrm{ASP}}+N_{\mathrm{CDS}}} \text { and } \frac{N_{\mathrm{CDS}}}{N_{\mathrm{ASP}}+N_{\mathrm{CDS}}}
$$

According to the IFSL Research (2009a, 2009b) reports, the attraction of bonds, and implicitly ASPs, as an investment has increased since the start of the credit crisis and large institutional, as well as retail, investors increased their holdings due to the losses on equity markets and due to the bonds and ASPs high returns as yields during 2008. ${ }^{32}$ On the other hand, there is a drop in both the notional amounts outstanding and the number of participants in the CDS market. ${ }^{33}$ Thus, if the crisis has affected activity in the CDS more severely than in the ASP market, we expect the ASPs to reveal information faster and more adequately than before the crisis, up to the point that ASPs could lead the process of price discovery in some cases. ${ }^{34}$

Hypothesis 2: Under scenarios with low liquidity leading to a generalized reduction in market participation in credit derivatives markets, the relative position of the ASP market as an information provider improves with respect to the one observed under high liquid scenarios.

Finally, we analyse the process of price discovery between ASP and bond spreads.

Hypothesis 3: The ASP market always (before and after the subprime crisis) leads the price discovery process with respect to the bond market.

\section{Data}

Our database contains daily data on Eurobonds and ASPs denominated in Euros and issued by non-financial companies that are collected from Reuters and on CDSs also denominated in Euros and issued by the same non-financial companies that are obtained from GFI.

GFI is a major inter-dealer broker, specializing in the trading of credit derivatives. GFI data contain single-name CDSs market prices for 1,2,3, 4 and 5 years maturities. These prices correspond to actual trades, or firm bids and offers where capital is actually committed and so they are not consensus or indications. Thus, these prices are an accurate indication of where the CDS markets have traded and closed for a given day. For some companies and for some maturities, especially 2 and 4 years, the data availability are scarce and in these cases, we employ mid-price quotes from a credit curve also reported by GFI to fill the missing data. ${ }^{35}$ GFI data have also 
been used by Hull, Predescu, and White (2004), Predescu (2006), Saita (2006), Nashikkar and Subrahmanyam (2007), Fulop and Lescourret (2007) or Nashikkar, Subrahmanyam, and Mahanti (2009) among others.

For each bond there is information on both bid and ask prices, the swap spread, the asset swap spread, the sector of the entity and its geographical location, the currency, the seniority, the rating history (Fitch, S\&P and Moody's ratings), the issuance date and the amount issued, the coupon and coupon dates and the maturity. We use bonds whose maturity at the investment dates is lower than five years. Several bonds issued by the same company may be used whenever they satisfy all the required criteria. The reason is that although CDS spread quotes refer to the issuer and not to an individual bond, asset swap spreads are quoted for individual bonds. Due to liquidity considerations, bonds with time to maturity equal to or less than 12 months to the date corresponding to their last observation are excluded. Moreover, our sample contains fixed-rate senior unsecured Euro denominated bonds whose issued quantity exceeds 300 million Euros. ${ }^{36}$ Other requirements imposed on bonds to be included in the sample are: (i) straight bonds, (ii) neither callable nor convertible, (iii) with rating history available, (iv) with constant coupons and with a fixed frequency, (v) without a sinking fund, (vi) without options, (vii) without an odd frequency of coupon payments, (viii) no government bonds and (ix) no inflation-indexed bonds. We cross-check the data on bonds with the equivalent data obtained from Datastream. Due to liquidity restrictions, investments are restricted to periods where there are 5-year CDS data on either actual trades or bids and offers where capital is committed.

The data spans from 1 November 2005 to 29 June 2009. However, we split the data into two subperiods to take into account the possible effects of the ongoing financial crisis. We estimate the break-points for each series of CDSs by means of the algorithm described in Bai and Perron (2003) for simultaneous estimation of multiple break-points. The ideas behind this implementation are described in Zeileis et al. (2003). The break-point is, on average, the 17 July 2007. For this reason, the first subperiod covers the period from 1 November 2005 to 16 July 2007 while the second one spans from 17 July 2007 to 29 June 2009. The final sample consists of 38 non-financial companies and 50 ASPs and bonds. ${ }^{37}$ Panels A and B of Table 1 reports the CDS spread, the asset swap spread, the bond spread and the bases descriptive statistics before and during crisis, respectively.

Table 1. Descriptive statistics.

\begin{tabular}{|c|c|c|c|c|c|c|c|c|}
\hline \multirow[b]{2}{*}{ Issuer } & \multicolumn{2}{|c|}{ CDS spread } & \multicolumn{2}{|c|}{ ASP spread (ASS) } & \multicolumn{2}{|c|}{ Bond spread (BS) } & \multirow{2}{*}{$\begin{array}{c}\text { Basis } \\
\text { ASS - CDS } \\
\text { Mean }\end{array}$} & \multirow{2}{*}{$\begin{array}{c}\text { Basis } \\
\text { BS }- \text { CDS } \\
\text { Mean }\end{array}$} \\
\hline & Mean & $\mathrm{SD}$ & Mean & SD & Mean & SD & & \\
\hline \multicolumn{9}{|l|}{ Panel A } \\
\hline Akzo I & 22.99 & 2.68 & 16.27 & 8.36 & 17.82 & 8.62 & -6.72 & -5.17 \\
\hline Akzo II & 13.46 & 3.91 & 15.31 & 5.63 & 16.54 & 5.28 & 1.84 & 3.08 \\
\hline BMW & 11.80 & 4.68 & 10.57 & 3.51 & 12.10 & 3.63 & -1.24 & 0.30 \\
\hline Bouygues I & 20.09 & 5.67 & 24.52 & 6.89 & 26.00 & 6.85 & 4.42 & 5.90 \\
\hline Bouygues II & 18.94 & 6.02 & 14.97 & 5.08 & 16.03 & 4.83 & -3.96 & -2.91 \\
\hline British AM Tob. I & 23.77 & 13.22 & 19.68 & 8.84 & 21.41 & 8.53 & -4.09 & -2.36 \\
\hline British AM Tob. II & 23.75 & 6.73 & 32.26 & 8.42 & 34.27 & 8.57 & 8.51 & 10.52 \\
\hline Carrefour I & 15.63 & 4.29 & 18.72 & 5.40 & 20.30 & 5.45 & 3.09 & 4.68 \\
\hline Carrefour II & 12.51 & 3.30 & 7.48 & 4.30 & 8.33 & 4.26 & -5.03 & -4.18 \\
\hline Casino I & 47.94 & 8.57 & 56.73 & 11.40 & 59.28 & 11.28 & 8.79 & 11.34 \\
\hline Casino II & 47.73 & 24.70 & 54.23 & 26.19 & 55.86 & 26.12 & 6.49 & 8.13 \\
\hline
\end{tabular}


Table 1. Continued.

\begin{tabular}{|c|c|c|c|c|c|c|c|c|}
\hline \multirow[b]{2}{*}{ Issuer } & \multicolumn{2}{|c|}{ CDS spread } & \multicolumn{2}{|c|}{ ASP spread (ASS) } & \multicolumn{2}{|c|}{ Bond spread (BS) } & \multirow{2}{*}{$\begin{array}{c}\text { Basis } \\
\text { ASS - CDS } \\
\text { Mean }\end{array}$} & \multirow{2}{*}{$\begin{array}{c}\text { Basis } \\
\mathrm{BS}-\mathrm{CDS} \\
\text { Mean }\end{array}$} \\
\hline & Mean & SD & Mean & SD & Mean & SD & & \\
\hline Compass Group & 26.32 & 18.28 & 35.19 & 19.90 & 36.13 & 19.37 & 8.87 & 9.82 \\
\hline Edison Spa & 15.88 & 3.07 & 18.67 & 5.17 & 19.98 & 5.31 & 2.80 & 4.10 \\
\hline Enel & 13.82 & 3.46 & 12.65 & 6.27 & 14.12 & 6.39 & -1.17 & 0.29 \\
\hline Energia de Portugal I & 11.01 & 4.78 & 10.85 & 4.00 & 11.77 & 3.75 & -0.16 & 0.75 \\
\hline Energia de Portugal II & 13.68 & 4.85 & 16.25 & 3.58 & 17.03 & 3.18 & 2.57 & 3.36 \\
\hline E.ON & 10.46 & 2.76 & 9.32 & 3.91 & 10.55 & 3.77 & -1.15 & 0.09 \\
\hline France Telecom & 20.42 & 8.34 & 19.67 & 7.97 & 20.06 & 7.34 & -0.75 & -0.36 \\
\hline Iberdrola I & 16.49 & 5.07 & 17.55 & 5.34 & 19.11 & 5.21 & 1.06 & 2.62 \\
\hline Iberdrola II & 11.29 & 3.16 & 10.25 & 3.44 & 11.69 & 3.36 & -1.05 & 0.40 \\
\hline Kingfisher & 47.86 & 8.68 & 48.81 & 9.50 & 51.10 & 9.35 & 0.95 & 3.24 \\
\hline Koninklijke KPN & 47.32 & 10.42 & 53.02 & 12.48 & 55.78 & 12.65 & 5.70 & 8.45 \\
\hline Louis Vuitton I & 19.34 & 5.38 & 23.77 & 7.71 & 25.31 & 7.78 & 4.42 & 5.96 \\
\hline Louis Vuitton II & 18.63 & 6.41 & 22.04 & 6.89 & 23.29 & 6.67 & 3.40 & 4.65 \\
\hline PPR & 43.62 & 6.20 & 49.93 & 7.14 & 51.16 & 7.00 & 6.31 & 7.54 \\
\hline Renault & 16.03 & 6.64 & 21.45 & 8.72 & 22.33 & 8.58 & 5.41 & 6.30 \\
\hline Repsol YPF & 21.07 & 6.80 & 27.16 & 7.37 & 27.81 & 6.92 & 6.09 & 6.74 \\
\hline Reuters & 19.04 & 5.66 & 25.79 & 5.63 & 27.20 & 5.53 & 6.76 & 8.16 \\
\hline Saint Gobain I & 17.95 & 4.37 & 17.75 & 5.00 & 19.18 & 5.08 & -0.19 & 1.23 \\
\hline Saint Goba & 26.14 & 5.95 & 31.77 & 8.04 & 33.90 & 8.16 & 5.63 & 7.77 \\
\hline Saint Gobain III & 21.64 & 6.22 & 26.83 & 7.74 & 28.14 & 7.60 & 5.19 & 6.50 \\
\hline Scania & 24.83 & 8.49 & 24.59 & 7.06 & 26.80 & 7.34 & -0.23 & 1.97 \\
\hline Siemens & 12.21 & 1.59 & 10.25 & 1.75 & 11.19 & 1.65 & -1.96 & -1.02 \\
\hline Sodexho & 10.17 & 4.97 & 19.38 & 5.60 & 20.63 & 5.18 & 9.22 & 10.47 \\
\hline Stora Enso & 36.02 & 11.22 & 37.94 & 11.12 & 41.21 & 11.66 & 1.92 & 5.19 \\
\hline Technip & 24.41 & 3.47 & 33.08 & 5.14 & 34.86 & 5.14 & 8.67 & 10.45 \\
\hline Telecom Italia I & 45.57 & 10.80 & 47.86 & 12.81 & 50.22 & 12.81 & 2.29 & 4.65 \\
\hline Telecom Italia II & 46.73 & 11.68 & 45.54 & 11.04 & 44.69 & 9.91 & -1.19 & -2.04 \\
\hline Telefonica & 34.22 & 9.86 & 37.60 & 9.87 & 40.36 & 10.07 & 3.38 & 6.14 \\
\hline Telekom Austria & 27.04 & 14.98 & 27.56 & 10.47 & 30.09 & 10.92 & 0.52 & 3.05 \\
\hline Tesco I & 9.35 & 4.93 & 11.85 & 4.81 & 13.12 & 4.81 & 2.51 & 3.78 \\
\hline Tesco II & 10.15 & 4.47 & 14.47 & 5.93 & 16.08 & 6.14 & 4.32 & 5.93 \\
\hline Thales & 13.62 & 3.03 & 18.66 & 4.64 & 20.21 & 4.71 & 5.04 & 6.60 \\
\hline Thyssenkrupp & 38.83 & 12.98 & 41.02 & 18.66 & 42.67 & 18.70 & 2.19 & 3.84 \\
\hline Union Fenosa & 20.10 & 8.35 & 24.49 & 6.98 & 25.61 & 6.72 & 4.39 & 5.51 \\
\hline Vinci & 22.62 & 6.89 & 22.48 & 5.72 & 23.40 & 5.56 & -0.14 & 0.77 \\
\hline Vivendi & 37.86 & 8.46 & 42.65 & 10.12 & 45.21 & 9.35 & 4.79 & 7.36 \\
\hline Vodafone & 15.93 & 3.80 & 13.33 & 7.18 & 15.03 & 7.32 & -2.60 & -0.90 \\
\hline Volkswagen & 21.66 & 5.81 & 24.25 & 7.61 & 26.16 & 7.83 & 2.59 & 4.50 \\
\hline Volvo & 20.32 & 6.88 & 21.69 & 7.73 & 22.80 & 7.59 & 1.37 & 2.48 \\
\hline Average & 23.37 & 7.06 & 25.76 & 7.88 & 27.28 & 7.80 & 2.40 & 3.91 \\
\hline \multicolumn{9}{|l|}{ Panel B } \\
\hline Akzo I & 22.91 & 13.77 & 15.77 & 13.08 & 15.23 & 13.39 & -7.14 & -7.67 \\
\hline Akzo II & 65.35 & 43.04 & 71.75 & 70.25 & 73.09 & 73.10 & 6.39 & 7.73 \\
\hline BMW & 143.30 & 145.26 & 97.84 & 103.52 & 100.27 & 106.85 & -45.46 & -43.03 \\
\hline Bouygues I & 102.37 & 67.46 & 101.73 & 65.78 & 99.32 & 64.96 & -0.63 & -3.05 \\
\hline Bouygues II & 46.74 & 20.56 & 28.48 & 13.32 & 26.13 & 13.78 & -18.26 & -20.61 \\
\hline British AM Tob. I & 21.75 & 13.04 & 27.88 & 13.73 & 26.59 & 15.03 & 6.13 & 4.84 \\
\hline British AM Tob. II & 59.05 & 28.23 & 107.48 & 61.30 & 109.66 & 62.00 & 48.43 & 50.61 \\
\hline
\end{tabular}


Table 1. Continued.

\begin{tabular}{|c|c|c|c|c|c|c|c|c|}
\hline \multirow[b]{2}{*}{ Issuer } & \multicolumn{2}{|c|}{ CDS spread } & \multicolumn{2}{|c|}{ ASP spread (ASS) } & \multicolumn{2}{|c|}{ Bond spread (BS) } & \multirow{2}{*}{$\begin{array}{c}\text { Basis } \\
\text { ASS - CDS } \\
\text { Mean }\end{array}$} & \multirow{2}{*}{$\frac{\begin{array}{c}\text { Basis } \\
\text { BS }- \text { CDS }\end{array}}{\text { Mean }}$} \\
\hline & Mean & SD & Mean & SD & Mean & SD & & \\
\hline Carrefour I & 49.78 & 28.57 & 52.85 & 43.52 & 50.35 & 42.18 & 3.07 & 0.57 \\
\hline Carrefour II & 47.36 & 31.76 & 30.36 & 19.34 & 28.90 & 26.65 & -17.00 & -18.46 \\
\hline Casino I & 142.42 & 76.61 & 172.68 & 96.59 & 177.36 & 100.39 & 30.26 & 34.94 \\
\hline Casino II & 129.82 & 82.17 & 111.39 & 62.01 & 127.01 & 86.35 & -18.43 & -2.81 \\
\hline Compass Group & 28.22 & 11.57 & 28.99 & 14.97 & 26.73 & 15.02 & 0.76 & -1.49 \\
\hline Edison Spa & 64.67 & 53.41 & 81.73 & 63.20 & 80.56 & 60.52 & 17.06 & 15.89 \\
\hline Enel & 181.47 & 169.90 & 53.62 & 40.81 & 53.68 & 40.98 & -127.85 & -127.79 \\
\hline Energia de Portugal I & 63.18 & 31.30 & 50.25 & 33.62 & 70.44 & 84.02 & -12.92 & 7.26 \\
\hline Energia de Portugal II & 72.19 & 34.54 & 101.37 & 66.28 & 99.56 & 66.46 & 29.18 & 27.37 \\
\hline E.ON & 29.97 & 15.03 & 23.24 & 11.17 & 20.90 & 10.61 & -6.73 & -9.07 \\
\hline France Telecom & 41.24 & 20.63 & 36.15 & 14.59 & 33.65 & 13.16 & -5.09 & -7.59 \\
\hline Iberdrola I & 91.91 & 58.70 & 75.33 & 57.46 & 73.77 & 56.47 & -16.57 & -18.13 \\
\hline Iberdrola II & 56.21 & 17.04 & 22.62 & 8.08 & 21.11 & 7.63 & -33.59 & -35.09 \\
\hline Kingfisher & 191.71 & 101.87 & 218.77 & 109.45 & 232.37 & 119.06 & 27.06 & 40.66 \\
\hline Koninklijke KPN & 72.67 & 28.30 & 113.49 & 55.43 & 118.28 & 59.64 & 40.82 & 45.61 \\
\hline Louis Vuitton I & 71.18 & 51.35 & 70.48 & 48.09 & 69 & 47.89 & -0.70 & -1.37 \\
\hline Louis Vuitton II & 65.82 & 54.71 & 8 & 49.64 & 60.81 & 48.82 & -3.63 & -5.00 \\
\hline PPR & 251.15 & 200.92 & 200.10 & 145.78 & 206.13 & 153.20 & -51.05 & -45.02 \\
\hline Renault & 5 & 40.11 & 34.95 & 13.50 & 32.73 & 13.39 & -23.79 & -26.02 \\
\hline Repsol YPF & 115.08 & 112.21 & 107.03 & 87.49 & 106.07 & 89.01 & -8.06 & -9.02 \\
\hline Reuters & 25.21 & 5.8 & 31.72 & 14.25 & 32.18 & 14.14 & 6.51 & 6.97 \\
\hline Saint Gobain I & 71.05 & 44.75 & 36.41 & 13.34 & 35.05 & 13.62 & -34.64 & -36.00 \\
\hline Saint Gobain II & 157.12 & 105.03 & 158.11 & 112.11 & 162.77 & 116.51 & 0.99 & 5.64 \\
\hline Saint Gobain III & 142.68 & 102.03 & 110.63 & 72.43 & 117.04 & 86.39 & -32.06 & -25.64 \\
\hline Scania & 53.84 & 22.69 & 52.89 & 17.10 & 55.32 & 17.84 & -0.96 & 1.47 \\
\hline Siemens & 75.68 & 56.84 & 62.26 & 47.49 & 61.29 & 46.75 & -13.42 & -14.39 \\
\hline Sodexho & 20.22 & 11.43 & 37.02 & 15.13 & 34.54 & 16.24 & 16.81 & 14.33 \\
\hline Stora Enso & 151.65 & 99.48 & 130.83 & 53.31 & 138.58 & 56.83 & -20.82 & -13.06 \\
\hline Technip & 98.15 & 80.35 & 109.03 & 83.60 & 113.56 & 89.44 & 10.88 & 15.41 \\
\hline Telecom Italia I & 183.94 & 140.76 & 157.81 & 96.93 & 171.91 & 120.12 & -26.14 & -12.03 \\
\hline Telecom Italia II & 185.40 & 138.37 & 216.94 & 150.62 & 215.83 & 152.30 & 31.54 & 30.44 \\
\hline Telefonica & 97.65 & 55.63 & 103.07 & 56.78 & 104.85 & 56.91 & 5.42 & 7.21 \\
\hline Telekom Austria & 58.36 & 30.30 & 94.18 & 63.32 & 99.73 & 66.06 & 35.82 & 41.36 \\
\hline Tesco I & 58.86 & 52.31 & 63.37 & 62.18 & 36.48 & 60.87 & 4.51 & -22.37 \\
\hline Tesco II & 63.58 & 49.52 & 7.35 & 54.03 & 66.59 & 53.57 & 3.77 & 3.01 \\
\hline Thales & 78.65 & 61.84 & 72.49 & 67.95 & 76.33 & 79.17 & -6.16 & -2.32 \\
\hline Thyssenkrupp & 173.81 & 157.73 & 104.64 & 96.12 & 112.44 & 105.46 & -69.17 & -61.37 \\
\hline Union Fenosa & 72.71 & 69.03 & 87.48 & 65.76 & 85.18 & 63.58 & 14.77 & 12.47 \\
\hline Vinci & 51.93 & 29.75 & 41.63 & 17.90 & 39.68 & 18.21 & -10.30 & -12.25 \\
\hline Vivendi & 62.87 & 27.14 & 80.13 & 38.10 & 82.10 & 39.92 & 17.26 & 19.24 \\
\hline Vodafone & 39.41 & 14.36 & 25.67 & 11.42 & 23.75 & 11.67 & -13.74 & -15.65 \\
\hline Volkswagen & 131.18 & 91.80 & 118.90 & 95.54 & 122.20 & 97.98 & -12.28 & -8.98 \\
\hline Volvo & 215.51 & 235.82 & 244.23 & 269.96 & 254.70 & 290.16 & 28.72 & 39.19 \\
\hline Average & 91.11 & 64.70 & 86.11 & 59.15 & 87.65 & 63.29 & -5.01 & -3.46 \\
\hline
\end{tabular}

Notes: This table reports the descriptive statistics (mean and standard deviation) for the CDS spread; the ASP spread; the bond spread; and the bases, which are obtained as the difference between the ASP and the CDS spreads and as the difference between the bond and the CDS spreads, all of them defined in basis points. Panel A reports the descriptive statistics for the period before the crisis (November 2005 to July 2007) and Panel B for the crisis period (July 2007 to June 2009). 


\section{Price discovery results}

We analyse the price discovery process in two different contexts. On the one hand, before July 2007 there exists a scenario of high liquidity where the number of market participants is higher than in the second period, which represents the illiquid scenario.

The process of price discovery is analysed from an equilibrium model based on an Error Correction Model and the long-run equilibrium condition is based on the existence of cointegration between credit spreads. Econometric details on the model estimation of the VECM defined in Equation (16) can be found in Juselius (2006).

Before the price discovery analysis, we firstly verify the series stationarity by means of a Ng-Perron unit root test. Table 2 shows that credit spreads are I(1) for the two periods considered in 46 of the total 50 cases which correspond to 50 different ASPs and bonds.

In Table 3, we report the Johansen (1991) cointegration test results for each reference entity whenever the CDS and ASP spreads are I(1) in the two periods. In 32 of the total 46 cases, we find cointegration between ASP and CDS spreads. We find cointegration between bond and CDS spreads in the same 32 cases. ${ }^{38}$ The number of cointegration relationships that we find is similar to one obtained in previous analyses. Norden and Weber (2004), Blanco, Brennan, and Marsh (2005) and Zhu (2006) find cointegration relationships between CDS and bond spreads in 36 of 58 cases, in 26 of 33 cases and in 15 of 24 cases, respectively. De Wit (2006) finds cointegration relationships between CDS and ASP spreads in 88 of 144 cases. With respect to ASP and bond spreads, we find evidence of cointegration between them for all the 46 cases. ${ }^{39}$ We then test why there is no cointegration between the ASP and CDS market. To achieve this, we run a Probit regression with heteroskedasticity robust standard errors for the total 92 cases studied in both subperiods, using as dependent variable a dummy variable that equals 1 if there is cointegration and 0 otherwise. In order to control and test the effect of the crisis, we create a dummy variable equal to one if a given case corresponds to the crisis period. The cointegration seems to be more frequent in bonds/ASPs with a high coupon rate and with a long time to maturity. The results suggest that the riskier the underlying bond or the longer the time to maturity, the more similar are the credit spreads in the long run. The first result is consistent with the increase in correlation across financial markets as the risk increases. The second result suggests that the deviations among credit spreads are higher close to the bond maturity. We use other explanatory variables such as the rating; the basis, which is defined as the difference between the ASP and CDS spreads; and the crisis dummy but none of them have a significant effect on cointegration. ${ }^{40}$

The analysis of price discovery is based on the VECM specification presented in Equations (15) and (16) and it is applied to the 32 cases, where we find a long-run equilibrium behaviour of the credit spreads series. The vector in Equation (16) represents the coefficients that determine the market contribution to price discovery. We conclude that a given market leads the process of price discovery whenever its corresponding price discovery metric $\left(\mathrm{GG}_{i}\right.$ for $\left.i=1,2\right)$ is higher than 0.5 . Both markets reveal information in an equally efficient way whenever the price discovery metrics are close to 0.5 for both markets $\left(0.45<\mathrm{GG}_{i}<0.55\right.$ for $\left.i=1,2\right)$. The $\mathrm{GG}_{i}$ price discovery metric is defined such that it has a lower bound of 0 and an upper bound of 1 in order to be consistent with the definition in Equation (18) and the meaning of this metric.

\subsection{The leadership of the CDS market before the crisis}

Panel A of Table 4 shows that during the period before the crisis, Hypothesis 1 is confirmed and the CDSs appear clearly as the more efficient market in $87.5 \%$ of the cases ( 28 cases). According 
Table 2. Unit root test for credit spreads.

\begin{tabular}{|c|c|c|c|c|c|c|}
\hline \multirow[b]{2}{*}{ Issuer } & \multicolumn{2}{|c|}{ CDS } & \multicolumn{2}{|c|}{ ASP } & \multicolumn{2}{|c|}{ Bond } \\
\hline & First period & Second period & First period & Second period & First period & Second period \\
\hline Akzo I & $\mathrm{I}(1)$ & $\mathrm{I}(1)$ & $\mathrm{I}(1)$ & $\mathrm{I}(1)$ & $\mathrm{I}(1)$ & $\mathrm{I}(1)$ \\
\hline Akzo II & $\mathrm{I}(1)$ & $\mathrm{I}(1)$ & $\mathrm{I}(1)$ & $\mathrm{I}(1)$ & $\mathrm{I}(1)$ & $\mathrm{I}(1)$ \\
\hline BMW & $\mathrm{I}(1)$ & $\mathrm{I}(1)$ & $\mathrm{I}(1)$ & $\mathrm{I}(1)$ & $\mathrm{I}(1)$ & $\mathrm{I}(1)$ \\
\hline Bouygues I & $\mathrm{I}(1)$ & $\mathrm{I}(1)$ & $\mathrm{I}(1)$ & $\mathrm{I}(1)$ & $\mathrm{I}(1)$ & $\mathrm{I}(1)$ \\
\hline Bouygues II & $\mathrm{I}(1)$ & $\mathrm{I}(1)$ & $\mathrm{I}(1)$ & $\mathrm{I}(1)$ & $\mathrm{I}(1)$ & $\mathrm{I}(1)$ \\
\hline British AM Tob. I & $\mathrm{I}(1)$ & $\mathrm{I}(1)$ & $\mathrm{I}(1)$ & $\mathrm{I}(1)$ & $\mathrm{I}(1)$ & $\mathrm{I}(1)$ \\
\hline British AM Tob. II & $\mathrm{I}(1)$ & $\mathrm{I}(1)$ & $\mathrm{I}(1)$ & $\mathrm{I}(1)$ & $\mathrm{I}(1)$ & $\mathrm{I}(1)$ \\
\hline Carrefour I & $\mathrm{I}(1)$ & $\mathrm{I}(1)$ & $\mathrm{I}(1)$ & $\mathrm{I}(1)$ & $\mathrm{I}(1)$ & $\mathrm{I}(1)$ \\
\hline Carrefour II & $\mathrm{I}(1)$ & $\mathrm{I}(1)$ & $\mathrm{I}(1)$ & $\mathrm{I}(1)$ & $\mathrm{I}(1)$ & $\mathrm{I}(1)$ \\
\hline Casino I & $\mathrm{I}(1)$ & $\mathrm{I}(1)$ & $\mathrm{I}(1)$ & $\mathrm{I}(1)$ & $\mathrm{I}(1)$ & $\mathrm{I}(1)$ \\
\hline Casino II & $\mathrm{I}(1)$ & $\mathrm{I}(1)$ & $\mathrm{I}(1)$ & $\mathrm{I}(1)$ & $\mathrm{I}(1)$ & $\mathrm{I}(1)$ \\
\hline Compass Group & $\mathrm{I}(1)$ & $\mathrm{I}(1)$ & $\mathrm{I}(1)$ & $\mathrm{I}(1)$ & $\mathrm{I}(1)$ & $\mathrm{I}(1)$ \\
\hline Edison Spa & $\mathrm{I}(1)$ & $\mathrm{I}(1)$ & $\mathrm{I}(1)$ & $\mathrm{I}(1)$ & $\mathrm{I}(1)$ & $\mathrm{I}(1)$ \\
\hline Enel & $\mathrm{I}(1)$ & $\mathrm{I}(1)$ & $\mathrm{I}(1)$ & $\mathrm{I}(1)$ & $\mathrm{I}(1)$ & $\mathrm{I}(1)$ \\
\hline Energia de Portugal I & $\mathrm{I}(1)$ & $\mathrm{I}(1)$ & $\mathrm{I}(1)$ & $\mathrm{I}(1)$ & $\mathrm{I}(1)$ & $\mathrm{I}(1)$ \\
\hline Energia de Portugal II & $\mathrm{I}(1)$ & $\mathrm{I}(1)$ & $\mathrm{I}(1)$ & $\mathrm{I}(1)$ & $\mathrm{I}(1)$ & $\mathrm{I}(1)$ \\
\hline E.ON & $\mathrm{I}(1)$ & $\mathrm{I}(1)$ & $\mathrm{I}(1)$ & $\mathrm{I}(1)$ & $\mathrm{I}(1)$ & $\mathrm{I}(1)$ \\
\hline France Telecom & $\mathrm{I}(1)$ & $\mathrm{I}(1)$ & $\mathrm{I}(1)$ & $\mathrm{I}(1)$ & $\mathrm{I}(1)$ & $\mathrm{I}(1)$ \\
\hline Iberdrola I & $\mathrm{I}(1)$ & $\mathrm{I}(1)$ & $\mathrm{I}(1)$ & $\mathrm{I}(1)$ & $\mathrm{I}(1)$ & $\mathrm{I}(1)$ \\
\hline Iberdrola II & $\mathbf{I}(\mathbf{1})$ & $\mathbf{I}(\mathbf{1})$ & I(1) & $\mathbf{I}(\mathbf{0})$ & $\mathbf{I}(\mathbf{1})$ & $\mathbf{I}(\mathbf{0})$ \\
\hline Kingfisher & $\mathrm{I}(1)$ & $\mathrm{I}(1)$ & $\mathrm{I}(1)$ & $\mathrm{I}(1)$ & $\mathrm{I}(1)$ & $\mathrm{I}(1)$ \\
\hline Koninklijke KPN & $\mathrm{I}(1)$ & $\mathrm{I}(1)$ & $\mathrm{I}(1)$ & $\mathrm{I}(1)$ & $\mathrm{I}(1)$ & $\mathrm{I}(1)$ \\
\hline Louis Vuitton I & $\mathrm{I}(1)$ & $\mathrm{I}(1)$ & $\mathrm{I}(1)$ & $\mathrm{I}(1)$ & $\mathrm{I}(1)$ & $\mathrm{I}(1)$ \\
\hline Louis Vuitton II & $\mathrm{I}(1)$ & $\mathrm{I}(1)$ & $\mathrm{I}(1)$ & $\mathrm{I}(1)$ & $\mathrm{I}(1)$ & $\mathrm{I}(1)$ \\
\hline PPR & $\mathrm{I}(1)$ & $\mathrm{I}(1)$ & $\mathrm{I}(1)$ & $\mathrm{I}(1)$ & $\mathrm{I}(1)$ & $\mathrm{I}(1)$ \\
\hline Renault & $\mathrm{I}(1)$ & $\mathrm{I}(1)$ & $\mathrm{I}(1)$ & $\mathrm{I}(1)$ & $\mathrm{I}(1)$ & $\mathrm{I}(1)$ \\
\hline Repsol YPF & $\mathrm{I}(1)$ & $\mathrm{I}(1)$ & $\mathrm{I}(1)$ & $\mathrm{I}(1)$ & $\mathrm{I}(1)$ & $\mathrm{I}(1)$ \\
\hline Reuters & $\mathbf{I}(\mathbf{0})$ & $\mathbf{I}(\mathbf{1})$ & $\mathbf{I}(\mathbf{1})$ & $\mathbf{I}(\mathbf{1})$ & $\mathbf{I}(\mathbf{1})$ & I(1) \\
\hline Saint Gobain I & $\mathrm{I}(1)$ & $\mathrm{I}(1)$ & $\mathrm{I}(1)$ & $\mathrm{I}(1)$ & $\mathrm{I}(1)$ & $\mathrm{I}(1)$ \\
\hline Saint Gobain II & $\mathrm{I}(1)$ & $\mathrm{I}(1)$ & $\mathrm{I}(1)$ & $\mathrm{I}(1)$ & $\mathrm{I}(1)$ & $\mathrm{I}(1)$ \\
\hline Saint Gobain III & $\mathrm{I}(1)$ & $\mathrm{I}(1)$ & $\mathrm{I}(1)$ & $\mathrm{I}(1)$ & $\mathrm{I}(1)$ & $\mathrm{I}(1)$ \\
\hline Scania & $\mathrm{I}(1)$ & $\mathrm{I}(1)$ & $\mathrm{I}(1)$ & $\mathrm{I}(1)$ & $\mathrm{I}(1)$ & $\mathrm{I}(1)$ \\
\hline Siemens & $\mathbf{I}(\mathbf{0})$ & $\mathbf{I}(\mathbf{1})$ & $\mathbf{I}(\mathbf{0})$ & $\mathbf{I}(\mathbf{1})$ & $\mathbf{I}(\mathbf{0})$ & I(1) \\
\hline Sodexho & $\mathrm{I}(1)$ & $\mathrm{I}(1)$ & $\mathrm{I}(1)$ & $\mathrm{I}(1)$ & $\mathrm{I}(1)$ & $\mathrm{I}(1)$ \\
\hline Stora Enso & $\mathrm{I}(1)$ & $\mathrm{I}(1)$ & $\mathrm{I}(1)$ & $\mathrm{I}(1)$ & $\mathrm{I}(1)$ & $\mathrm{I}(1)$ \\
\hline Technip & $\mathrm{I}(1)$ & $\mathrm{I}(1)$ & $\mathrm{I}(1)$ & $\mathrm{I}(1)$ & $\mathrm{I}(1)$ & $\mathrm{I}(1)$ \\
\hline Telecom Italia I & $\mathrm{I}(1)$ & $\mathrm{I}(1)$ & $\mathrm{I}(1)$ & $\mathrm{I}(1)$ & $\mathrm{I}(1)$ & $\mathrm{I}(1)$ \\
\hline Telecom Italia II & $\mathrm{I}(1)$ & $\mathrm{I}(1)$ & $\mathrm{I}(1)$ & $\mathrm{I}(1)$ & $\mathrm{I}(1)$ & $\mathrm{I}(1)$ \\
\hline Telefonica & $\mathrm{I}(1)$ & $\mathrm{I}(1)$ & $\mathrm{I}(1)$ & $\mathrm{I}(1)$ & $\mathrm{I}(1)$ & $\mathrm{I}(1)$ \\
\hline Telekom Austria & $\mathrm{I}(1)$ & $\mathrm{I}(1)$ & $\mathrm{I}(1)$ & $\mathrm{I}(1)$ & $\mathrm{I}(1)$ & $\mathrm{I}(1)$ \\
\hline Tesco I & $\mathrm{I}(1)$ & $\mathrm{I}(1)$ & $\mathrm{I}(1)$ & $\mathrm{I}(1)$ & $\mathrm{I}(1)$ & $\mathrm{I}(1)$ \\
\hline Tesco II & $\mathrm{I}(1)$ & $\mathrm{I}(1)$ & $\mathrm{I}(1)$ & $\mathrm{I}(1)$ & $\mathrm{I}(1)$ & $\mathrm{I}(1)$ \\
\hline Thales & $\mathbf{I}(\mathbf{0})$ & I(1) & $\mathbf{I}(\mathbf{0})$ & I(1) & $\mathbf{I}(\mathbf{0})$ & I(1) \\
\hline Thyssenkrupp & $\mathrm{I}(1)$ & $\mathrm{I}(1)$ & $\mathrm{I}(1)$ & $\mathrm{I}(1)$ & $\mathrm{I}(1)$ & $\mathrm{I}(1)$ \\
\hline Union Fenosa & $\mathrm{I}(1)$ & $\mathrm{I}(1)$ & $\mathrm{I}(1)$ & $\mathrm{I}(1)$ & $\mathrm{I}(1)$ & $\mathrm{I}(1)$ \\
\hline Vinci & $\mathrm{I}(1)$ & $\mathrm{I}(1)$ & $\mathrm{I}(1)$ & $\mathrm{I}(1)$ & $\mathrm{I}(1)$ & $\mathrm{I}(1)$ \\
\hline Vivendi & $\mathrm{I}(1)$ & $\mathrm{I}(1)$ & $\mathrm{I}(1)$ & $\mathrm{I}(1)$ & $\mathrm{I}(1)$ & $\mathrm{I}(1)$ \\
\hline Vodafone & $\mathrm{I}(1)$ & $\mathrm{I}(1)$ & $\mathrm{I}(1)$ & $\mathrm{I}(1)$ & $\mathrm{I}(1)$ & $\mathrm{I}(1)$ \\
\hline Volkswagen & $\mathrm{I}(1)$ & I(1) & $\mathrm{I}(1)$ & $\mathrm{I}(1)$ & $\mathrm{I}(1)$ & I(1) \\
\hline Volvo & $\mathrm{I}(1)$ & $\mathrm{I}(1)$ & $\mathrm{I}(1)$ & $\mathrm{I}(1)$ & $\mathrm{I}(1)$ & $\mathrm{I}(1)$ \\
\hline
\end{tabular}

Notes: This table reports the unit root tests for CDS, ASP and bond spreads in two different periods. The first column is divided in two sub-columns that present the order of integration of the CDS premium for the period before the crisis (November 2005 to July 2007) and the crisis (July 2007 to June 2009), respectively. The second column is divided into other two columns that present the order of integration for the ASP spreads for the same two periods. The last column reports the order of integration for the bond spreads for the same periods. The cases where all the credit spreads are not integrated of order one in the two periods are in bold. 
Table 3. Cointegration tests based on CDS and ASP spreads.

\begin{tabular}{|c|c|c|c|c|}
\hline \multirow[b]{2}{*}{ Issuer } & \multicolumn{2}{|c|}{ November 2005 to July 2007} & \multicolumn{2}{|c|}{ July 2007 to June 2009} \\
\hline & None & At most 1 & None & At most 1 \\
\hline Akzo I & $13.93^{* *}$ & 0.36 & $16.81^{* *}$ & 1.99 \\
\hline Akzo II & $20.42^{* * *}$ & 3.98 & $13.02^{* *}$ & 3.24 \\
\hline BMW & $14.88^{* *}$ & 3.75 & $28.87^{* * *}$ & 3.01 \\
\hline Bouygues I & $13.74^{* *}$ & 2.77 & $18.07^{* *}$ & 2.04 \\
\hline Bouygues II & $19.98^{* *}$ & 4.47 & $20.01^{* *}$ & 5.89 \\
\hline British AM Tob. I & 21.14** & 2.30 & 6.40 & 2.38 \\
\hline British AM Tob. II & $21.84^{* *}$ & 8.10 & 7.46 & 2.72 \\
\hline Carrefour I & $13.70^{* *}$ & 0.11 & $13.58^{* *}$ & 0.58 \\
\hline Carrefour II & $20.05^{* *}$ & 6.12 & $13.03^{* *}$ & 0.48 \\
\hline Casino I & $26.90^{* * *}$ & 4.00 & $22.29^{* *}$ & 1.86 \\
\hline Casino II & $20.18^{* *}$ & 2.41 & $24.92^{* * *}$ & 3.34 \\
\hline Compass Group & $49.43^{* * *}$ & 5.41 & $17.13^{* *}$ & 3.03 \\
\hline Edison Spa & $13.21^{* *}$ & 3.56 & $20.75^{* *}$ & 2.38 \\
\hline Enel & $21.83^{* *}$ & 1.64 & 10.79 & 1.97 \\
\hline Energia de Portugal I & $22.80^{* *}$ & 8.42 & 6.88 & 2.70 \\
\hline Energia de Portugal II & $17.44^{* * *}$ & 3.23 & $12.60^{* *}$ & 0.00 \\
\hline E.ON & $15.36^{* *}$ & 1.67 & $24.11^{* *}$ & 2.18 \\
\hline France Telecom & 16.40 & 3.82 & 8.17 & 2.13 \\
\hline Iberdrola I & $14.19^{* *}$ & 2.90 & $22.41^{* *}$ & 2.55 \\
\hline Kingfisher & $42.19^{* * *}$ & 6.21 & $21.78^{* *}$ & 3.11 \\
\hline Koninklijke KPN & $13.22^{* *}$ & 3.57 & $23.32^{* *}$ & 4.13 \\
\hline Louis Vuitton I & $17.30^{* *}$ & 0.60 & $21.26^{* *}$ & 2.36 \\
\hline Louis Vuitton II & $15.16^{* *}$ & 2.43 & $32.78^{* * *}$ & 2.79 \\
\hline PPR & $17.85^{* *}$ & 1.34 & $21.80^{* *}$ & 2.03 \\
\hline Renault & $15.57^{* *}$ & 0.93 & $15.46^{* *}$ & 1.97 \\
\hline Repsol YPF & $13.74^{* *}$ & 1.70 & $26.70^{* * *}$ & 2.38 \\
\hline Saint Gobain I & $21.67^{* *}$ & 6.45 & 9.67 & 2.24 \\
\hline Saint Gobain II & $12.67^{* *}$ & 3.04 & $16.47^{* *}$ & 1.59 \\
\hline Saint Gobain III & $20.77^{* *}$ & 4.78 & $20.77^{* * *}$ & 0.01 \\
\hline Scania & 7.33 & 2.82 & $20.302^{* *}$ & 2.41 \\
\hline Sodexho & $17.36^{* *}$ & 3.50 & $13.06^{* *}$ & 0.01 \\
\hline Stora Enso & 15.60 & 4.20 & 11.69 & 4.50 \\
\hline Technip & 12.01 & 1.60 & $21.47^{* *}$ & 2.93 \\
\hline Telecom Italia I & $23.71^{* *}$ & 1.69 & $25.43^{* * *}$ & 2.62 \\
\hline Telecom Italia II & $12.98^{* *}$ & 0.60 & $20.10^{* *}$ & 2.32 \\
\hline Telefonica & $16.41^{* *}$ & 1.75 & $20.10^{* *}$ & 2.78 \\
\hline Telekom Austria & $19.99^{* *}$ & 9.14 & 12.43 & 3.65 \\
\hline Tesco I & 11.42 & 3.41 & $24.48^{* *}$ & 2.70 \\
\hline Tesco II & $27.13^{* * *}$ & 3.65 & $21.25^{* *}$ & 2.33 \\
\hline Thyssenkrupp & $19.18^{* *}$ & 1.82 & $16.93^{* *}$ & 0.16 \\
\hline Union Fenosa & $19.67^{* *}$ & 6.01 & $13.23^{* *}$ & 0.10 \\
\hline Vinci & $14.26^{* *}$ & 2.62 & 5.70 & 0.53 \\
\hline Vivendi & 12.58 & 1.15 & 7.76 & 3.26 \\
\hline Vodafone & $21.00^{* *}$ & 3.56 & $17.95^{* * *}$ & 0.21 \\
\hline Volkswagen & 10.31 & 3.27 & $22.94^{* *}$ & 2.78 \\
\hline Volvo & $17.17^{* *}$ & 3.76 & $12.54^{* *}$ & 0.06 \\
\hline
\end{tabular}

Notes: This table reports the results obtained in the cointegration analyses applied to the CDS and the ASP spreads. The first two columns of Table 3 report Johansen trace test statistics for the number of cointegrating relations between the CDS and the ASP spreads for the period before the subprime crisis (November 2005 to July 2007). The last two columns of Table 3 report the same statistics for the crisis period (July 2007 to June 2009). A constant is included in the long-run relation if it is significantly different from zero. The number of lags in the vector autoregression is optimized using the AIC and attending to the autocorrelation LM residual test such that there is no autocorrelation at an adequate lag order. The cases where we do not find evidence of cointegration between credit spreads for the two periods are given in bold.

* Rejection of null at $10 \%$ level.

** Rejection of null at $5 \%$ level.

*** Rejection of null at $1 \%$ level. 
Table 4. Contributions to price discovery (CDS vs. ASP).

\begin{tabular}{|c|c|c|c|c|c|c|c|c|c|}
\hline Issuer & $\alpha_{1}$ & $t$-Stat & $\alpha_{2}$ & $t$-Stat & $\beta_{3}$ & $\beta_{2}$ & $\mathrm{PD}_{1}$ & $\mathrm{PD}_{2}$ & $\mathrm{GG}_{1}$ \\
\hline \multicolumn{10}{|c|}{ Panel A: Contributions to price discovery (CDS vs. ASP) before the crisis } \\
\hline kzo I & -0.037 & -2.607 & -0.005 & -0.619 & 0.000 & 0.580 & -0.146 & 1.085 & 0.000 \\
\hline kzo II & -0.075 & -3.786 & 0.004 & & 0.000 & 1.152 & 0.050 & .942 & .050 \\
\hline BMW & -0.085 & -3.023 & -0.015 & -1. & 0.000 & 0.771 & -0.198 & & .000 \\
\hline Bouygues I & -0.0 & -1.3 & 0.016 & & 0.000 & & & & .507 \\
\hline Bouyge & & -1 & 0.041 & & 0.133 & 64 & & & 550 \\
\hline arrefour I & & -2 & -0.015 & -1 & & & 74 & & 000 \\
\hline arrefour II & 0.101 & -3.418 & 0.008 & 0.527 & 10.492 & 1.461 & & & .072 \\
\hline I & 0.089 & -4.310 & -0.034 & -1.354 & 37 & 1.213 & -0 & & .000 \\
\hline Casino II & 0.050 & -2.634 & 0.013 & 0.6 & 3.205 & 1.048 & 0.200 & & 202 \\
\hline ss Group & -0.094 & -5.141 & 0.008 & 0 . & 29.194 & 0.631 & 84 & 47 & .081 \\
\hline diso & -0.018 & -1.145 & 0.022 & 2.6 & 0.000 & 1 & & & .547 \\
\hline nergic & -0.021 & -1.159 & 0.023 & 3. & 0.000 & 1. & & 10 & .522 \\
\hline. $\mathrm{ON}$ & -0.092 & -3.307 & 0.011 & & 0.000 & 0.920 & & 00 & .108 \\
\hline rola I & -0.054 & -2.661 & 0.019 & 2.1 & 0.000 & 1.096 & 0.250 & 0.726 & .256 \\
\hline .1ng & -0.163 & -6.045 & 0.006 & 0.1 & -3.706 & 1.077 & 0. & 54 & .033 \\
\hline KPN & -0.074 & -1.8 & 0.073 & 2.3 & 0.000 & 1.129 & 0. & .472 & .498 \\
\hline ou & -0.116 & -3.4 & 0.0 & 2.1 & -2.542 & 1.3 & 0.2 & & .216 \\
\hline ouls & -0.094 & -3.5 & 0. & 0. & 0.000 & 1.1 & & & .072 \\
\hline P & -0.036 & -3 & 0.0 & 2. & 13.492 & & & & .402 \\
\hline & -0.112 & -2 & & & & & & & .402 \\
\hline & -00 & -3 & & & & & & & .023 \\
\hline & 00 & -2 & & & & & & & .146 \\
\hline & 0. & -2 & & & & & & & 0.303 \\
\hline & -0 . & -1 & & & 73 & & & & 0.462 \\
\hline & -0 & -3 & & & -7.878 & 1. & & & 0.375 \\
\hline Гel & -0 & -2 & & & 0 & & & & 496 \\
\hline & & -2 & & & & & & & 467 \\
\hline & & -2 & -0 & -3 & 9 & 0 & 5 & & .000 \\
\hline & 1 & -3 & & & -14 & & & & 432 \\
\hline & 3 & -2 & & & & & & & 037 \\
\hline od & -0 . & -2 & -0 & -1 & -9 & 1.443 & -0 & & 0.000 \\
\hline Jol & -0.070 & -3 & -0.003 & -0.3 & -7 & 1.460 & -0 & & 0.000 \\
\hline & -0.068 & -2.883 & 0.018 & 1.104 & -0.755 & 1.173 & 0.119 & 0.837 & 0.227 \\
\hline 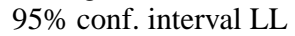 & -0.080 & & 0.00 & & -3.457 & 1.077 & & & 0.151 \\
\hline UL & -0.057 & & 0.028 & & 1.947 & 1.270 & & & 0.302 \\
\hline \multicolumn{10}{|c|}{ Panel B: Contributions to price discovery (CDS vs. ASP) during the crisis } \\
\hline $\mathrm{kzc}$ & -0.068 & -2.878 & & 2.063 & -33.021 & & & & .233 \\
\hline 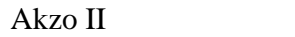 & -0.011 & -0.374 & & 2.009 & 0.000 & & & 0.406 & 0.651 \\
\hline BMW & -0.045 & -1.527 & & & 0.000 & 0.667 & & 0.495 & 0.605 \\
\hline Bou & -0.011 & -0.369 & 0.065 & 3.346 & -3.965 & 1.029 & 0.831 & 0.145 & 0.852 \\
\hline Bouy & -0.030 & -1.267 & 0.058 & 2.893 & 3.483 & 0.513 & 0.964 & 0.506 & 0.656 \\
\hline Carre & -0.018 & -0.8861 & 0.034 & 2.832 & 0.000 & 1.169 & 0.585 & 0.316 & 0.649 \\
\hline Carrefour II & -0.036 & -1.258 & 0.061 & 3.089 & 0.000 & 0.562 & 0.867 & 0.512 & 0.629 \\
\hline Casi & -0.022 & -1.401 & 58 & 3.717 & -20.117 & 1.354 & 595 & 194 & 0.754 \\
\hline & -( & -3 & & & 98 & 0.755 & & & 0.041 \\
\hline Group & & -2.142 & & & -0.647 & & & & 0.222 \\
\hline & & -1 & & & & & & & 0.646 \\
\hline Energic & -0.0 & -3. & & & 0.000 & & & & 0.166 \\
\hline E.ON & -0.015 & -0.604 & 0.025 & 2.340 & 5.165 & 0.586 & 0.840 & 0.507 & 0.623 \\
\hline
\end{tabular}


Table 4. Continued.

\begin{tabular}{lccccrcccc}
\hline Issuer & $\alpha_{1}$ & $t$-Stat & $\alpha_{2}$ & $t$-Stat & \multicolumn{1}{c}{$\beta_{3}$} & $\beta_{2}$ & $\mathrm{PD}_{1}$ & $\mathrm{PD}_{2}$ & $\mathrm{GG}_{1}$ \\
\hline Iberdrola I & -0.037 & -1.364 & 0.101 & 4.096 & -19.347 & 1.010 & 0.726 & 0.267 & 0.732 \\
Kingfisher & -0.126 & -3.339 & 0.068 & 1.682 & 45.657 & 1.029 & 0.348 & 0.642 & 0.351 \\
Koninklijke KPN & -0.066 & -2.676 & 0.014 & 1.340 & -31.071 & 1.643 & 0.153 & 0.749 & 0.169 \\
Louis Vuitton I & -0.046 & -2.065 & 0.078 & 3.466 & 2.706 & 0.949 & 0.647 & 0.386 & 0.626 \\
Louis Vuitton II & -0.054 & -2.055 & 0.082 & 4.315 & 4.995 & 0.857 & 0.658 & 0.437 & 0.601 \\
PPR & -0.059 & -2.339 & 0.127 & 2.980 & 16.282 & 0.718 & 0.844 & 0.394 & 0.682 \\
Renault & -0.062 & -1.110 & 0.132 & 3.068 & 10.265 & 0.594 & 0.938 & 0.443 & 0.679 \\
Repsol YPF & -0.010 & -0.384 & 0.126 & 4.919 & 13.871 & 0.800 & 1.142 & 0.087 & 0.929 \\
Saint Gobain II & -0.027 & -1.841 & 0.039 & 2.576 & -17.603 & 1.109 & 0.558 & 0.381 & 0.594 \\
Saint Gobain III & -0.115 & -4.3677 & 0.021 & 1.001 & 0.000 & 0.764 & 0.160 & 0.878 & 0.154 \\
Sodexho & -0.017 & -0.592 & 0.053 & 3.527 & 0.000 & 2.239 & 0.392 & 0.123 & 0.761 \\
Telecom Italia I & -0.115 & -4.569 & 0.001 & 0.021 & 45.865 & 0.636 & 0.005 & 0.997 & 0.005 \\
Telecom Italia II & -0.071 & -1.702 & 0.088 & 2.562 & 13.265 & 1.104 & 0.522 & 0.424 & 0.552 \\
Telefonica & -0.030 & -0.898 & 0.082 & 2.975 & -4.623 & 1.073 & 0.692 & 0.257 & 0.729 \\
Tesco II & -0.004 & -0.159 & 0.087 & 4.140 & -5.743 & 1.073 & 0.892 & 0.043 & 0.954 \\
Thyssenkrupp & -0.030 & -1.571 & 0.043 & 2.156 & 2.880 & 0.527 & 0.823 & 0.567 & 0.592 \\
Union Fenosa & -0.007 & -0.478 & 0.077 & 3.583 & 0.000 & 1.025 & 0.894 & 0.083 & 0.915 \\
Vodafone & -0.031 & -0.8451 & 0.043 & 2.118 & 0.000 & 0.672 & 0.723 & 0.516 & 0.584 \\
Volvo & -0.068 & -1.898 & 0.045 & 2.581 & 0.000 & 1.229 & 0.364 & 0.552 & 0.397 \\
Average & -0.047 & -1.725 & 0.057 & 2.709 & 1.847 & 0.992 & 0.591 & 0.463 & 0.554 \\
95\% conf. interval LL & -0.059 & & 0.044 & & -4.209 & 0.855 & & & 0.461 \\
UL & -0.035 & & 0.070 & & 7.903 & 1.129 & & & 0.647 \\
\hline
\end{tabular}

Notes: This table reports the price discovery analysis results. Panel A reports the contributions to price discovery of CDS and ASP spreads $\left(s_{t}^{A}\right.$ and $\left.\bar{s}_{t-j}\right)$ during the period before the subprime crisis. Panel B presents the contribution of the previous spreads during the crisis. The measures of price discovery are based on the following system of two equations:

$$
\begin{aligned}
\Delta s_{t}^{A} & =\alpha_{1}\left(s_{t-1}^{A}-\beta_{3}-\beta_{2} \bar{s}_{t-1}\right)+\sum_{j=1}^{p} \delta_{1, j} \Delta s_{t-j}^{A}+\sum_{j=1}^{p} \eta_{1, j} \Delta \bar{s}_{t-j}+u_{1, t} \\
\Delta \bar{s}_{t} & =\alpha_{2}\left(s_{t-1}^{A}-\beta_{3}-\beta_{2} \bar{s}_{t-1}\right)+\sum_{j=1}^{p} \delta_{2, j} \Delta s_{t-j}^{A}+\sum_{j=1}^{p} \eta_{2, j} \Delta \bar{s}_{t-j}+u_{2, t} .
\end{aligned}
$$

The values of coefficients $\alpha_{1}, \alpha_{2}, \beta_{1}$ and $\beta_{2}^{\mathrm{a}}$ and the $t$-statistics of coefficients $\alpha_{\mathrm{s}}$ are reported in Panels A and B. The columns are named by the coefficients themselves. The last three columns in Panels A and B report the price discovery measure attributed to the ASP $\left(\mathrm{PD}_{1}\right)$, the price discovery measure attributed to the $\mathrm{CDS}\left(\mathrm{PD}_{2}\right)$ and the percentage of price discovery attributed to the ASP market $\left(\mathrm{GG}_{1}\right)$ which is equivalent to the Gonzalo and Granger price discovery metric attributed to the ASP market for a parameter $\beta_{2}$ equal to 1 . The ASP market leads the process of price discovery whenever $\mathrm{GG}_{1}$ is higher than 0.5 . However, when $\mathrm{GG}_{1}$ is below a value of 0.5 , the CDS market leads the process of price discovery. The last rows in Panels A and B show the average coefficient or metric and the corresponding lower limit (LL) and upper limit (UL) for their $95 \%$ confidence interval.

${ }^{\text {a }}$ The parameters $\beta_{2}$ and $\beta_{3}$ which are reported in Panels $\mathrm{A}$ and $\mathrm{B}$ of Table 4 are significant at $5 \%$ level in all the cases.

to our model, the role of price discovery leadership comes from the relative number of market participants in the CDS with respect to the ASP market. An implication of the above results is that the market activity in Euro-denominated corporate bonds and ASPs is more limited than in CDS markets. A possible explanation is that the former are often held by investors until maturity which affects in a negative sense during periods of high liquidity their role as information providers. The ASP market reflects credit risk more efficiently in the remaining four cases. In eight cases, we observe that the CDS market reveals information as efficiently as the ASP market $\left(\mathrm{GG}_{1}\right.$ is between 0.45 and 0.55). According to Equation (18), the last eight cases where both markets 
reveal information in an equally efficient way could be explained by a higher market participation of the agents who operate in both markets $\left(N_{\text {BOTH }}\right.$ is high). On average, we find that the CDS market leads the ASP market during the period before the crisis as the value of 0.227 for the corresponding GG average metric in the ASP market reveals. The 95\% confidence interval for the average GG metric is 0.151-0.302, where even the upper limit implies that the CDS market leads the ASP market. The minimum GG metric is 0, which means that the CDS market reveals all the information, while the maximum is 0.55 .

\subsection{The leadership of the ASP and bond markets during the crisis}

Panel B of Table 4 reports the results for the subprime crisis period. Comparing Panels A and B of Table 4, we observe that during the crisis, ASP spreads reveal more efficiently credit risk than before. This result is consistent with Hypothesis 2 up to the point that in $71.88 \%$ of the cases (23 cases), ASP spreads lead CDS spreads in the price discovery process. The CDS market reflects credit risk more efficiently in the remaining nine cases. Thus, ASPs' predominant position as information providers during the crisis is in line with the evidence reported in the IFSL Research (2009a, 2009b) about CDS and bond notional amounts outstanding and trading activity. Dötz (2007) states that the turbulence in the credit markets in spring 2005 was apparently handled much better by the bond market than by the CDS market. The role of ASP as information providers improves with respect to the one observed before the crisis in $84.4 \%$ of the cases (27 cases). This role only worsens in five cases which could be explained by a drop in the ASPs' liquidity that even exceeds the drop in CDS liquidity. On average, we find that the ASP market leads the CDS market during the crisis as the value of 0.554 for the corresponding GG average metric reveals. The $95 \%$ confidence interval for the average GG metric is 0.461 to 0.647 . The minimum GG metric is 0.005 , which means that the CDS market reveals almost all the information, while the maximum is 0.954 , which means that the ASP market reveals almost all the information. The range for this metric is wider than in the period before crisis which may be related to a decrease in the presence of the agents that operate in both markets. This idea is reinforced because in Panel B of Table 4, we do not find any GG metric close to $0.5(0.45<\mathrm{GG}<0.55)$. Comparing results before and during the crisis, the ASP spreads reveal credit risk more efficiently during than before the crisis given that the average GG measure during the crisis ( 0.554 with a standard deviation of 0.258$)$ is almost 2.5 times the one observed before the crisis $(0.227$ with a standard deviation of 0.209). We then test whether pre and during-crisis GG measures are different. The average difference $(0.327)$ is significantly greater than zero with asymptotic $t$-statistic equal to 5.3 ( $p$-value $\approx 0$ ). Also, using a test of means, we obtain that the average GG measure during the crisis is higher than the average GG measure before the crisis with asymptotic $t$-statistic equal to 2.7 ( $p$-value $\approx 0.005$ ). Panels $\mathrm{A}$ and $\mathrm{B}$ of Figure 1 help to understand these results given that there is one main determinant of price discovery that we are considering in this paper: liquidity. We realize that there is no generally held definition of liquidity. Many other measures have been suggested in the literature. In fact there is a close relationship between many of the measures and actual transactions costs, and the assumption that liquidity proxies measure liquidity seems to be granted, see Goyenko, Holden and Trzcinka (2009). The analysis of price discovery is extended to the case where the informational efficiency of CDS spreads are compared with bond spreads. Results are similar to the ones presented for CDS and ASP spreads and Hypotheses 1 and 2 also hold. ${ }^{41}$

Other factors that may influence the price discovery process across markets are the CTD option embedded in the CDS, a potential illiquidity premium and the existence of a high counterparty 
Table 5. Bootstrap estimation of the significance level of the price discovery metrics.

\begin{tabular}{|c|c|c|c|c|c|c|}
\hline Issuer & $\mathrm{GG}(\mathrm{CDS})$ & $t$-Stat & $p$-Val & GG(ASP) & $t$-Stat & $p$-Val \\
\hline Akzo I & 1.000 & 369.499 & 0.000 & 0.233 & -29.107 & 1.000 \\
\hline Akzo II & 0.950 & 29.214 & 0.000 & 0.651 & 12.216 & 0.000 \\
\hline BMW & 1.000 & 62.696 & 0.000 & 0.605 & 6.407 & 0.000 \\
\hline Bouygues I & 0.493 & -0.689 & 0.755 & 0.852 & 17.237 & 0.000 \\
\hline Bouygues II & 0.450 & -4.255 & 1.000 & 0.656 & 7.960 & 0.000 \\
\hline Carrefour I & 1.000 & 158.322 & 0.000 & 0.649 & 24.527 & 0.000 \\
\hline Carrefour II & 0.928 & 63.718 & 0.000 & 0.629 & 16.713 & 0.000 \\
\hline Casino I & 1.000 & 159.017 & 0.000 & 0.754 & 14.534 & 0.000 \\
\hline Casino II & 0.798 & 27.359 & 0.000 & 0.041 & -67.913 & 1.000 \\
\hline Compass Group & 0.919 & 51.098 & 0.000 & 0.222 & -41.068 & 1.000 \\
\hline Edison Spa & 0.453 & -4.647 & 1.000 & 0.646 & 10.407 & 0.000 \\
\hline Energia de Portugal II & 0.478 & -2.390 & 0.991 & 0.166 & -27.630 & 1.000 \\
\hline E.ON & 0.892 & 198.328 & 0.000 & 0.623 & 8.809 & 0.000 \\
\hline Iberdrola I & 0.744 & 29.706 & 0.000 & 0.732 & 12.883 & 0.000 \\
\hline Kingfisher & 0.967 & 47.427 & 0.000 & 0.351 & -13.782 & 1.000 \\
\hline Koninklijke KPN & 0.502 & 0.080 & 0.468 & 0.169 & -41.129 & 1.000 \\
\hline Louis Vuitton I & 0.784 & 61.625 & 0.000 & 0.626 & 6.382 & 0.000 \\
\hline Louis Vuitton II & 0.928 & 44.549 & 0.000 & 0.601 & 7.035 & 0.000 \\
\hline PPR & 0.598 & 17.425 & 0.000 & 0.682 & 15.184 & 0.000 \\
\hline Renault & 0.598 & 12.688 & 0.000 & 0.679 & 10.335 & 0.000 \\
\hline Repsol YPF & 0.977 & 42.715 & 0.000 & 0.929 & 29.679 & 0.000 \\
\hline Saint Gobain II & 0.854 & 21.746 & 0.000 & 0.594 & 2.104 & 0.018 \\
\hline Saint Gobain III & 0.697 & 23.907 & 0.000 & 0.154 & -42.130 & 1.000 \\
\hline Sodexho & 0.538 & 4.207 & 0.000 & 0.761 & 27.442 & 0.000 \\
\hline Telecom Italia I & 0.625 & 16.017 & 0.000 & 0.005 & -52.782 & 1.000 \\
\hline Telecom Italia II & 0.504 & 0.727 & 0.234 & 0.552 & 0.078 & 0.469 \\
\hline Telefonica & 0.533 & 2.817 & 0.002 & 0.729 & 17.927 & 0.000 \\
\hline Tesco II & 1.000 & 119.058 & 0.000 & 0.954 & 33.782 & 0.000 \\
\hline Thyssenkrupp & 0.568 & 9.903 & 0.000 & 0.592 & 6.755 & 0.000 \\
\hline Union Fenosa & 0.963 & 32.525 & 0.000 & 0.915 & 24.949 & 0.000 \\
\hline Vodafone & 1.000 & 89.653 & 0.000 & 0.584 & 6.705 & 0.000 \\
\hline Volvo & 1.000 & 93.904 & 0.000 & 0.397 & -10.677 & 1.000 \\
\hline
\end{tabular}

Notes: In this table we present the estimates of the $t$-statistics which are employed to test whether a given GG metric is significantly higher than 0.5 before and during the crisis for the CDS and the ASP markets, respectively. These hypotheses are tested by means of $t$-statistics which are constructed using the bootstrapped standard errors. Columns 2 and 3 report the results obtained when we test if the GG metrics for the CDS market, column 1, are higher than 0.5 before the crisis. Columns 5 and 6 report the results obtained when we test if the GG metrics for the ASP market, column 4, are higher metrics for the ASP market, column 4, are higher than 0.5 during the crisis. Columns 1 and 4 are extracted from Panels $\mathrm{A}$ and $\mathrm{B}$ of Table 4.

risk in the CDS. Regarding the first two factors, Ammer and Cai (2007) find that the main reason supporting the price leadership of bond spreads with respect to CDS premiums is the existence of a higher CTD option and the illiquidity. Actually, these two factors as well as the counterparty risk are assumed to be more influential during the current subprime crisis and it is precisely in this period when we find that both ASP and bond markets reflect the information more efficiently that the CDS market.

For the cases in which the credit spreads are I(1) but the existence of cointegration is rejected, the VECM representation is not valid. For these cases, we use a price discovery analysis on the basis of a Granger causality test for a VAR in first differences and for the three same periods. ${ }^{42}$ According to the $p$-value of the chi-square statistics of the Granger causality test and the sum of 
the coefficients on lagged spreads which are significantly different from zero, we conclude that in the first subperiod, CDS prices Granger-cause ASP spreads for 5 of the 14 cases, we find causation in the opposite direction in two cases, bidirectional causation in one case and no causation in the remaining six cases. In the second subperiod, we find that ASP spreads Granger-cause CDS prices in three of the fourteen cases, we find causation in the opposite direction in one case, bidirectional causation in five cases and no causation in the remaining five cases. The sum of the significant coefficients on lagged CDS and ASP spreads confirm the results of the Granger causality test.

Table 6. Contributions to price discovery (bond vs. ASP).

\begin{tabular}{|c|c|c|}
\hline & November 2005 to July 2007 & July 2007 to June 2009 \\
\hline Issuer & $\mathrm{GG}_{1}$ metric & $\mathrm{GG}_{1}$ metric \\
\hline Akzo I & 0.696 & 1.000 \\
\hline Akzo II & 0.640 & 0.801 \\
\hline BMW & 0.705 & 1.000 \\
\hline Bouygues I & 0.634 & 1.000 \\
\hline Bouygues II & 1.000 & 0.683 \\
\hline British AM Tob. I & 1.000 & 1.000 \\
\hline British AM Tob. II & 1.000 & 1.000 \\
\hline Carrefour I & 0.607 & 0.856 \\
\hline Carrefour II & 0.346 & 1.000 \\
\hline Casino I & 0.732 & 1.000 \\
\hline Casino II & 1.000 & 0.787 \\
\hline Compass Group & 0.800 & 0.653 \\
\hline Edison Spa & 1.000 & 1.000 \\
\hline Enel & 0.701 & 0.619 \\
\hline Energia de Portugal I & 0.985 & 0.967 \\
\hline Energia de Portugal II & 1.000 & 0.694 \\
\hline E.ON & 0.622 & 1.000 \\
\hline France Telecom & 0.670 & 1.000 \\
\hline Iberdrola I & 0.635 & 1.000 \\
\hline Kingfisher & 0.842 & 1.000 \\
\hline Koninklijke KPN & 0.730 & 0.737 \\
\hline Louis Vuitton I & 0.864 & 0.980 \\
\hline Louis Vuitton II & 1.000 & 0.869 \\
\hline PPR & 1.000 & 1.000 \\
\hline Renault & 0.614 & 0.254 \\
\hline Repsol YPF & 1.000 & 1.000 \\
\hline Saint Gobain I & 0.874 & 0.427 \\
\hline Saint Gobain II & 1.000 & 1.000 \\
\hline Saint Gobain III & 0.653 & 0.839 \\
\hline Scania & 0.712 & 1.000 \\
\hline Sodexho & 0.843 & 1.000 \\
\hline Stora Enso & 0.603 & 1.000 \\
\hline Technip & 1.000 & 0.825 \\
\hline Telecom Italia I & 0.556 & 0.832 \\
\hline Telecom Italia II & 0.844 & 1.000 \\
\hline Telefonica & 0.745 & 1.000 \\
\hline Telekom Austria & 0.708 & 1.000 \\
\hline Tesco II & 0.556 & 0.949 \\
\hline
\end{tabular}


Table 6. Continued.

\begin{tabular}{|c|c|c|}
\hline & November 2005 to July 2007 & July 2007 to June 2009 \\
\hline Issuer & $\mathrm{GG}_{1}$ metric & $\mathrm{GG}_{1}$ metric \\
\hline Thyssenkrupp & 0.723 & 0.915 \\
\hline Union Fenosa & 0.565 & 1.000 \\
\hline Vinci & 0.750 & 1.000 \\
\hline Vivendi & 0.883 & 1.000 \\
\hline Vodafone & 0.488 & 0.525 \\
\hline Volkswagen & 0.983 & 1.000 \\
\hline Volvo & 0.622 & 1.000 \\
\hline Average & 0.781 & 0.893 \\
\hline $95 \%$ confidence interval LL & 0.729 & 0.841 \\
\hline UL & 0.833 & 0.945 \\
\hline
\end{tabular}

Notes: This table reports the contributions to price discovery of bond and ASP spreads $\left(b s_{t}\right.$ and $\left.s_{t}^{A}\right)$. The first column presents the contribution of ASP spreads with respect to bond spreads during the period before the crisis. A value equal to or higher to 0.5 indicates that ASP markets lead bond markets in the process of price discovery while a value equal to or higher than 1 indicates that negligible information about credit risk is reported by bond spreads relative to the one reported by ASP spreads. The second column reports the same information for the crisis period. As in Table 4, the measures of price discovery are based on the following system of two equations:

$$
\begin{aligned}
& \Delta s_{t}^{A}=\alpha_{1}\left(s_{t-1}^{A}-\beta_{3}-\beta_{2} b s_{t-1}\right)+\sum_{j=1}^{p} \delta_{1, j} \Delta s_{t-j}^{A}+\sum_{j=1}^{p} \eta_{1, j} \Delta b s_{t-j}+u_{1, t} \\
& \Delta b s_{t}=\alpha_{2}\left(s_{t-1}^{A}-\beta_{3}-\beta_{2} b s_{t-1}\right)+\sum_{j=1}^{p} \delta_{2, j} \Delta s_{t-j}^{A}+\sum_{j=1}^{p} \eta_{2, j} \Delta b s_{t-j}+u_{2, t} .
\end{aligned}
$$

We directly report the Gonzalo and Granger metric $\left(\mathrm{GG}_{1}\right)$ that is obtained as the ratio between the price discovery measure attributed to the ASP $\left(\mathrm{PD}_{1}\right)$ and the sum of $\mathrm{PD}_{1}$ and $\mathrm{PD}_{2}$, where $\mathrm{PD}_{2}$ is the price discovery measure attributed to the bond. This ratio indicates the percentage of price discovery attributed to the ASP.

As a robustness test and to overcome the shortcoming that the precision of our estimates cannot be assessed analytically, we use the bootstrap method for cointegrated systems developed by Li and Maddala (1997). We choose to bootstrap from the estimated residuals of the VECM in order not to distort the dynamic structure of our model. Using estimated parameters and initial values, we create a new set of system variables (with the same number of observations as in the original data) by drawing observations randomly with replacement from the innovations. Based upon the generated data, the common trend relationship and the subsequent price discovery measures are re-estimated. This process is then repeated 1000 times and the standard errors are calculated from the empirical distribution. Finally, we test whether the corresponding GG metric is significantly higher than 0.5 before and during the crisis for both markets. To test these hypotheses, we construct a $t$-statistic using the bootstrapped standard errors. Results are reported in Table 5. Before the crisis, the CDS spreads lead, in most cases, the price discovery process with respect to the ASP spreads. During the crisis, the roles are reversed being the ASP spreads lead CDS spreads in the price discovery process. ${ }^{43}$

\subsection{Comparing the informational efficiency of the ASP and bond spreads}

In Table 6, we show that Hypothesis 3, which states that the ASP market reflects credit risk more efficiently than the bond market, is consistent with the empirical evidence for the two periods of 
time analysed. This result confirms empirically for the first time, at least to our knowledge, that the ASP spread is a better measure for credit risk than bond spreads are. Only in two of a total of 46 cases in the first subperiod, do bond spreads lead ASP spreads. This occurs in two cases in the second subperiod. The reason that explains these results may be a higher relative liquidity in the ASP market, which means that the number of market participants in the ASP market (liquidity) is greater than the number of players in the bond market.

\section{Conclusions}

We find that liquidity does affect the price discovery process in credit derivatives markets. We make three contributions to the literature. Firstly, we offer a theoretical model for testing price discovery in credit derivatives markets that allows for simultaneous agent participation in different markets. Secondly, we analyse the price discovery process between ASPs and CDSs and find that the leadership, in terms of price discovery, between ASPs and CDSs is very sensitive to the appearance of the subprime crisis. Before the crisis, the CDS market leads the ASP market but during the crisis the ASP market leads the CDS market. Thirdly, to our knowledge, this is the first price discovery analysis based on the ASP and bond markets. We find, according to GS terms, that the bond market is a 'pure satellite' of the asset swap market. Thus, the ASP spread is a more accurate measure of credit risk than the bond spread. For this reason, it seems more appropriate to use the ASP spread as an alternative or as a complement to the CDS rather than the bond spread.

Finally, we highlight the four main policy implications that emerge from our study and which could be of special interest for investors and regulators alike. First, we find that during the crisis, the ASP market reveals credit risk more efficiently that the CDS market. Reasons explaining this finding include the CTD option embedded in the CDS spread, the liquidity premium and the counterparty risk in CDSs. ${ }^{44}$ The key implication of this result is that inferences on the creditworthiness of a given firm based solely in CDS spreads in periods of high market turbulence and low liquidity are bound to be misleading. Second, we find that the ASP spread leads the price discovery process of credit risk more efficiently than the bond spread, before and during the crisis. For this reason, it is more appropriate to use the ASP spread as an alternative or as a complement to the CDS spread as a measure of credit risk rather than the bond spread. However, most of the existing literature has focused primarily on the bond and CDS spreads ignoring the role of the ASP spread as a credit risk indicator. Third, our theoretical model and empirical results highlight the importance of the agents that operate in both markets $\left(N_{\mathrm{BOTH}}\right)$ in order to provide stability to the credit markets. The arbitrageurs also play a special role in these markets given that their demands are defined in terms of a long-run equivalence or adjustment which could reduce deviations from the equilibrium prices. Fourth, the debt hedgers do not play any apparent role in the price discovery process if they are fully hedged. However, when they only hedge a given proportion of the total investment in ASPs or bonds, they also contribute to the price discovery process.

\section{Acknowledgements}

We are grateful to the Editors of this special issue: John Wilson, Barbara Casu, and David McMillan for their useful comments. We owe thanks to two anonymous referees for many astute comments that considerably improved the study. We also thank Isabel Figuerola-Ferretti, Javier Gil, Carlos González-Aguado, Jesús Gonzalo, Neil Kellard, María Rodríguez, Pedro Serrano, Javier Suárez and seminar participants at the XVII Foro de Finanzas and at the Emerging Scholars in Banking and Finance Conference at Cass Business School for all their comments and suggestions. Sergio Mayordomo and 
Juan Ignacio Peña acknowledge financial support from MICINN Grant Ref: ECO2009-12551. Juan Romo acknowledges financial support from MICINN Grant Ref: ECO2008-05080. The usual disclaimer applies.

\section{Notes}

1. Acharya and Schaefer (2006) posit that the liquidity risk can be defined as unpredictable changes in transaction costs and in liquidity. These adverse liquidity shocks, systematic or idiosyncratic, are mainly due to high and negative changes in financial products' returns and reduce the amount of capital available to financial intermediaries which lowers the ability of their trading desk to provide liquidity.

2. The value of CDSs outstanding at the end of 2004,2005 and 2006 was $\$ 8.42, \$ 17.1$ and $\$ 34.4$ trillion, respectively. The CDS market exploded over the past decade to more than $\$ 45$ trillion in mid-2007 and more than $\$ 62$ trillion in the second half of the same year, according to the ISDA. The size of the CDS market in mid-2007 is roughly twice the size of the US stock market (which is valued at about \$22 trillion) and far exceeds the \$7.1 trillion mortgage market and \$4.4 trillion US treasuries market. However, the notional amount outstanding decreased to \$38.6 trillion at the end of 2008 .

3. The main reason is the existence of a higher CTD option due to the higher risk of borrowers and also to liquidity reasons given that the higher the number of bonds issued, which they use as a liquidity measure, the more difficult is that the CDS market leads price discovery.

4. According to Dötz (2007), the relatively large contribution of the CDS market to price discovery is not necessarily tantamount to general and lasting improvement in the processing of information; the turbulence in the credit markets in the spring of 2005 was apparently handled much better by the bond market than by the CDS market. The weaknesses of the CDSs are likely to consist in the relatively high concentration and homogeneousness of its market players, whose herding behaviour, particularly in times of crisis, can strain liquidity, amplify market volatility and hamper price discovery.

5. Chan-Lau and Kim (2004) relate the same three financial instruments but for emerging market sovereign issuers. In most countries, they do not find any equilibrium price relationship between equity and bond markets and in terms of price discovery, it is difficult to conclude that one particular market dominates the price discovery process.

6. As far as we know, the relationship between ASP and CDS has only been treated in De Wit (2006). However, the perspective adopted in De Wit (2006) is based on the long-run equilibrium that should exist, and which the author finds, between ASP and CDS, ignoring the price discovery process.

7. Although we develop the case of CDS and ASP prices, the model can also be applied to study the interaction between CDS and bond spreads or between ASP and bond spreads.

8. A popular arbitrage strategy employed by hedge funds in credit derivatives markets defines the correct price from a long-term equilibrium price based on the cointegration methodology. The arbitrageur is betting only that the spread between the two cointegrated assets will narrow, which can be understood as a permanent adjustment process towards an economic equilibrium.

9. As Dötz (2007) state, the market for synthetic CDO products, which as opposed to cash CDS products are not backed by bonds or loans but by CDSs, presents some advantages such as the better availability of CDSs relative to bonds or loans and the heavy demand among investors for unfunded supersenior tranches.

10. We may also find protection sellers who hedge their positions, again, in the CDS market or individuals that participate in the CDS market in order to hedge their exposures to other institutions that are not due to debt positions.

11. We include this type of agents in order to make the model more comprehensive, given that the nature of CDSs is to provide insurance. In fact, CDSs are usually used to manage the credit risk.

12. As CDSs are over-the-counter (OTC) instruments, it is possible to buy a CDS contract whose maturity coincides with the bond's maturity and whose premium payments timing is agreed by the parties. As the bond's maturity date approaches, the use of CDSs with a 5-year constant maturity would lead to overhedging, given that the maturity dates of CDSs and asset swaps do not coincide. The consequence is that the investor will pay a CDS spread above the one needed to be fully hedged. Thus, we take advantage of the range of CDSs maturities to fit a CDS curve using a Piecewise Cubic Hermite Interpolating Polynomial algorithm that allows us to match asset swap and CDS maturities. This method is also used in Levin, Perli, and Zakrajšek (2005).

13. In order to proceed in this way, we assume that the investor can borrow money at Euribor flat.

14. If $s_{t}^{A}-\bar{s}_{t}>0$, then a profitable arbitrage opportunity exists. The investor should take long positions in both CDS and ASP and borrow the required quantity of money in order to finance the investment at 3 months Euribor. If $s_{t}^{A}-\bar{s}_{t}<0$, the inverse strategy will lead to an arbitrage opportunity. 
15. A combination of short positions on both the CDS and ASP leads to a net payment for the investor equal to the difference between CDS and ASP spreads, $\bar{s}_{t}-s_{t}^{A}$.

16. The net payoff is also zero at coupon payment dates while at the bond's maturity, as in every quarterly payment, the net payoff is equal to the basis.

17. Assumption A1 is necessary to reach a two-sided bound on the CDS rate and to guarantee that the equivalence relationship holds.

18. An example of a statistical arbitrage analysis in credit derivatives markets according to the technique and concept introduced Hogan et al. (2004) can be found in Mayordomo, Peña, and Romo (2009).

19. Cossin and Lu (2005) state that the liquidity premium, the CTD option and the market segmentation explain the pricing differences between bonds and CDS. The effect of the CTD option is more important as default risk increases.

20. If the two markets price credit risk equally in the long run, then their prices should be cointegrated with cointegrating vector $[1,-1, \mathrm{c}]$, suggesting a stationary basis.

21. Shorting a corporate bond or an ASP with a required maturity, even years, is not an easy task. The short sale of bonds or ASPs could be done via a repurchase agreement (repo) but as Blanco, Brennan, and Marsh (2005) explain, it is impossible to borrow a bond via a repo. The reason is that repo market for corporate bonds is illiquid and even if it is possible to short a bond via a repo, the tenor of the agreement would be short. Schonbucher (2003) states that this limitation could be solved by issuing credit-linked notes linked to the corresponding bond and selling them to the investors in the asset swap market. This alternative presents other limitations given that the issuance of credit-linked notes takes time and implies high fixed cost. This fact implies that deviations in the equivalence relationship might not imply arbitrage opportunities whenever an asset swap short sale is needed. Thus, in some cases traders are not able to exploit price differentials when the CDS premium is higher than the asset swap spread and as Blanco, Brennan, and Marsh (2005) suggest, this asymmetry may affect significantly the dynamic adjustment of credit spreads. The restrictions on short-sales could be even more severe in periods of financial distress.

22. These individual interpret that $R_{i, t}^{\mathrm{CDS}}$ is the CDS price, given its probability of default. As the market price $\bar{s}_{t}$ is above the reservation price, the investor is interested in selling protection in exchange of $\bar{s}_{t}$.

23. Note that the total endowments can increase exogenously from period $t$ to period $t+1$, for instance, by means of CDS or bond issuances.

24. The idea is that under the assumptions employed when defining the arbitrageurs demand, the fact that the ASP spread is a good indicator, although not perfect, of the CDS spread and given that both spreads are prices of the credit risk of a given firm, it seems reasonable to assume that the elasticities are similar.

25. The objective of this paper is not related with the literature of credit risk pricing and so, Equations (10) and (11) are not pricing equations of credit risk, such as the ones defined from the probability of default and recovery rates, but simply the ASP and CDS prices that clear both markets.

26. We do not report the whole expression of $u_{t}$ in order to save space and also, because of the assumptions on residuals they are not going to appear in our analysis.

27. Although hedgers are not important in the price discovery process, they must be included in the model because these individuals really participate in credit markets and we need them in order to make the model more comprehensive.

28. This decline in trading during the second half of 2008 reflects a combination of significantly reduced risk appetite, expectations of stable low interest rates in major markets and lower hedge fund activity. Exchange rate movements may also have affected to this decline. Most institutions report their positions in US dollars and the euro and the pound sterling depreciated by $30 \%$ and $12 \%$, respectively, against the US dollar between June and December 2008.

29. During the first quarter of 2009 , issuance of investment grade corporate bonds in Europe totalled a record $€ 140 \mathrm{bn}$, well above quarterly levels of less than $€ 50 \mathrm{bn}$ seen in recent years. It is motivated, among other reasons, by the use of bond markets for funding and the government guarantees to aid to the bond issuance. IFSL Research (2009b) reports that the amounts outstanding on the global bond market, which includes bonds, notes and money market instruments, increased $6 \%$ in 2008 to $\$ 83$ trillion.

30. See for instance Norden and Weber (2004), Blanco, Brennan, and Marsh (2005), Zhu (2006), Baba and Inada (2007), Dötz (2007), Forte and Peña (2009) and Coudert and Gex (2010).

31. In a limit case, if $N_{\text {BOTH }}$ tends to infinity, the price discovery is equal to 0.5 .

32. Allocation to bonds from high-net-worth individuals increased from $27 \%$ to $29 \%$ during 2008 with equities seeing the largest decline in their share of portfolio allocation.

33. The nominal of CDSs with respect to ASP contracts serves to show how in periods of financial distress it is much more difficult to participate in CDS than in ASP markets. The standard bond's faced value is $€ 1000$ while the CDS typical notional amount is $€ 10-20$ million for investment grade credits and $€ 2-5$ million for high yield credits.

34. Ammer and Cai (2007) state that the main reason to support that bond spreads lead CDS premiums is the existence of a higher CTD option and for liquidity reasons. In particular they employ as a liquidity measure the number of 
bonds outstanding by a given firm and find that the higher the number of bonds the less likely it is that CDSs will lead price discovery. Under illiquid scenarios, the CTD option embedded in CDS becomes more valuable and the liquidity premium to bear liquidity risk increases.

35. The GFI FENICS ${ }^{\circledR}$ Credit curve gives preference to real trades and quoted mid- points where available, and in their absence, it is based on the calculation of a running point level using the John Hull and Alan White methodology to ensure a credit curve always exists for each reference entity. This curve is a good approximation for CDSs at any maturity as several error analyses reveal. The median of the absolute difference in basis points between five years CDS premiums as defined from credit curve and the actual quotes or transaction prices for the period between April 2001 and May 2002, is equal to 1.16, 2.01 and 3.82 basis points for AAA/AA, A and BBB ratings for a total of 2659, 9585 and 8170 companies, respectively. Moreover, market CDS spread could be different from what we are assuming to be the true CDS spread by as much as 3.725 bps. on average.

36. This limit is set in order to avoid the selection of bonds with a small volume which could require higher transaction costs due to their reduced liquidity.

37. Our initial sample was 285 corporate bond issuers. We found a total of $116 €$ denominated bonds that mature before February 2012 but only 67 of them include information on 5-year bid/ask CDS spreads, asset swap spreads and Fenics Curve for at least 90 trading days. Of these, two bonds have been discarded because the issued amount does not exceed 300 millions of Euros, another four bonds were discarded because they were not investment grade bonds throughout the whole sample period. Another four bonds were discarded because their asset swap spreads were persistently negative and, finally, seven bonds were discarded because prices were too far from par.

38. We do not report these results because they are similar to the ones presented in Table 3 . However, these results are available upon request.

39. Cointegration test detailed results for ASP and bond spreads are available upon request.

40. The detailed results are available upon request.

41. Results of this analysis are available upon request.

42. These results are available upon request.

43. The $t$-statistics presented in Table 5 are obtained using the GG metrics reported in Table 4. Moreover, we employ the average GG metric obtained across the 1000 bootstrap repetitions and obtain similar results.

44. Amato and Remolona (2003) state that when it turns out to be very costly to undertake transactions in a given instrument, the investors must be compensated for it. This compensation is reinforced in the presence of uncertainty about the liquidity (or illiquidity) of an ASP, bond or CDS at a given time, and thus the investors could require a premium to bear this risk. This liquidity premium has been proved to exist both in CDS and bond markets. Longstaff, Mithal and Neis (2005) and Tang and Yan (2007) among others support the presence of a liquidity premium in CDS spreads. Collin-Dufresne, Goldstein, and Martin (2001), Perraudin and Taylor (2003), Elton et al. (2001), Delianedis and Geske (2001) and Chen, Lesmond, and Wei (2007) among others find that liquidity is an additional factor to credit risk which is present in bond spreads.

45. We do not report the whole expression of $u_{t}$ in order to save space and also, because of the assumptions on residuals they are not going to appear in our analysis.

\section{References}

Acharya, V., and S. Schaefer. 2006. Liquidity risk and correlation risk: Implications for risk management. Working Paper, London Business School.

Acharya, V., S. Schaefer, and Y. Zhang. 2007. Liquidity risk and correlation risk: A clinical study of the General Motors and Ford Downgrade of May 2005. Working Paper, SSRN.

Amato, J., and E. Remolona. 2003. The credit spread puzzle. BIS Quarterly Review, December: 51-63.

Ammer, J., and F. Cai. 2007. Sovereign CDS and bond pricing dynamics in emerging markets: Does the cheapest-to-deliver option matter? International Finance Discussion Papers Number 912, Board of Governors of the Federal Reserve System.

Baba, N., and M. Inada. 2007. Price discovery of credit spreads for Japanese mega-banks: Subordinated bond and CDS. Duscussion Paper 2007-E-6, Institute for Monetary and Economic Studies, Bank of Japan.

Bai, J., and P. Perron. 2003. Computation and analysis of multiple structural change models. Journal of Applied Econometrics 18: 1-22.

Blanco, F., S. Brennan, and I.W. Marsh. 2005. An empirical analysis of the dynamic relation between investment grade bonds and credit default swaps. Journal of Finance 60, no. 5: 2255-81. 
Chan-Lau, J.A., and Y.S. Kim. 2004. Equity prices, credit default swaps, and bond spreads in emerging markets. Working Paper, IMF.

Chen, L., D.A. Lesmond, and J. Wei. 2007. Corporate yield spreads and bond liquidity. The Journal of Finance 62, no. 1: 119-49.

Collin-Dufresne, P., R. Goldstein, and S. Martin. 2001. The determinants of credit spread changes. Journal of Finance 56, no. 6: 2177-207.

Cossin, D., and H. Lu. 2005. Are European corporate bonds and default swap markets segmented? Working Paper 153, FAME.

Coudert, V., and M. Gex. 2010. Contagion inside the credit default swaps market: The case of the GM and Ford crisis in 2005. Journal of International Financial Markets, Institutions and Money 20, no. 2: 109-34.

De Jong, F., and J. Driessen. 2006. Liquidity risk premia in corporate bond markets. Working Paper, University of Amsterdam.

De Wit, J. 2006. Exploring the CDS-bond basis. Working Paper, National Bank of Belgium.

Delianedis, G., and R. Geske. 2001. The components of corporate credit spreads: Default, recovery, tax, jumps, liquidity, and market factors. Working Paper, University of California.

Dötz, N. 2007. Time-varying contributions by the corporate bond and CDS markets to credit risk price discovery. Discussion Paper Series 2: Banking and Financial Studies No 08, Deutsche Bundesbank.

Elton, E., D. Gruber, D. Agrawal, and C. Mann. 2001. Explaining the rate spread on corporate bonds. Journal of Finance 56, no. 1: 247-77.

Engle, R., and C.W.J. Granger. 1987. Co-integration and error correction: Representation, estimation, and testing. Econometrica 55, no. 2: 251-76.

Felsenheimer, J. 2004. CDS: Mechanism, pricing and application. HVB Global Markets Research, 2 June.

Figuerola-Ferretti, I., and J. Gonzalo. 2010. Modelling and measuring price discovery in commodity markets. Journal of Econometrics 158, no. 1: 95-107.

Forte, S., and J.I. Peña. 2009. Credit spreads: An empirical analysis on the informational content of stocks, bonds and CDS. Journal of Banking and Finance 33, no. 11: 2013-25.

Francis, C., A. Kakodkar, and B. Martin. 2003. Credit derivative handbook 2003. Merrill Lynch Global Securities Research and Economics Group.

Fulop, A., and L. Lescourret. 2007. An analysis of intra-daily patterns on the CDS market. Working Paper, ESSEC Business School.

Garbade, K.D., and W.L. Silver. 1983. Price movements and price discovery in commodity markets. Review of Economics and Statistics 65, no. 2: 289-97.

Gonzalo, J., and C.W.J. Granger. 1995. Estimation of common long-memory components in cointegrated systems. Journal of Business and Economics Statistics 13, no. 1: 27-35.

Goyenko, R.Y., C.W. Holden, and C.A. Trzcinka. 2009. Do liquidity measures measure liquidity? Journal of Financial Economics 92, no. 2: 153-81.

Hasbrouck, J. 1995. One security, many markets: Determining the contributions to price discovery. Journal of Finance 50, no. 4: 1175-99.

Hogan, S., R.A. Jarrow, M. Teo, and M. Warachka. 2004. Testing market efficiency using statistical arbitrage with applications to momentum and value strategies. Journal of Financial Economics 73, no. 3: 525-65.

Hull, J., M. Predescu, and A. White. 2004. The relationship between credit default swap spreads, bond yields, and credit rating announcements. Journal of Banking and Finance 28: 2789-811.

International Financial Services London (IFSL) Research. 2009a. Derivatives 2009.

International Financial Services London (IFSL) Research. 2009b. Bond Markets 2009.

Johansen, S. 1991. Estimation and hypothesis testing of co-integration vectors in gaussian vector autoregressive models. Econometrica 59, no. 6: 1551-80.

Juselius, K. 2006. The cointegrated VAR model: Methodology and applications. Oxford: Oxford University Press.

Levin, A., R. Perli, and E. Zakrajšek. 2005. The determinants of market frictions in the corporate market. Working Paper, Federal Reserve Board, Washington.

Li, H., and G.S. Maddala. 1997. Bootstrapping cointegrating regressions. Journal of Econometrics 80, no. 2: $297-313$.

Longstaff, F.A., S. Mithal, and E. Neis. 2005. Corporate yield spreads: Default risk or liquidity? New evidence from the credit default swap market. Journal of Finance 60, no. 5: 2213-53.

Mayordomo, S., J.I. Peña, and J. Romo. 2009. Are there arbitrage opportunities in credit derivatives markets? A new test and an application to the case of CDS and ASPs. Working Paper, Universidad Carlos III de Madrid.

Nashikkar, A.J., and M.G. Subrahmanyam. 2007. Latent liquidity and corporate bond yield spreads. NYU Working Paper No. FIN-07-013. 
Nashikkar, A.J., M.G. Subrahmanyam, and S. Mahanti. 2009. Limited arbitrage and liquidity in the market for credit risk. NYU Working Paper No. FIN-08-011.

Norden, L., and M. Weber. 2004. Informational efficiency of credit default swap and stock markets: The impact of credit ratings announcements. Journal of Banking and Finance 28, no. 11: 2813-43.

Perraudin, W., and A. Taylor. 2003. Liquidity and bond market spreads. Working Paper, Bank of England.

Predescu, M. 2006. The performance of structural models of default for firms with liquid CDS spreads. Working Paper, Rotman School of Management, University of Toronto.

Saita, L. 2006. The puzzling price of corporate default risk. Working Paper, Standford Graduate School of Business.

Schonbucher, P.J. 2003. Credit derivatives pricing models: Models, pricing, implementation. Wiley Finance.

Stein, J.L. 1961. The simultaneous determination of spot and future prices. The American Economic Review 51, no. 5: $1012-25$.

Tang, D.Y., and H. Yan. 2007. Liquidity and credit default swap spreads. Working Paper, Kennesaw State University.

Working, H. 1948. Theory of the inverse carrying charge in futures markets. Journal of Farm Economics 30, no. 1: 1-28.

Yan, B., and E. Zivot. 2007. The dynamics of price discovery. Working Paper Series, University of Washington.

Zeileis, A., C. Kleiber, W. Krämer, and K. Hornik. 2003. Testing and dating of structural changes in practice. Computational Statistics and Data Analysis 44, nos. 1-2: 109-23.

Zhu, H. 2006. An empirical comparison of credit spreads between the bond market and the credit default swap market. Journal of Financial Services Research 29, no. 3: 211-35.

\section{Appendix 1}

In order to obtain an expression for the credit spreads we substitute the expressions (14) into the Equations (10) and (11) and obtain the following equation:

$$
\left(\begin{array}{c}
s_{t}^{A} \\
\bar{s}_{t}
\end{array}\right)=\frac{H \beta_{3}}{B}\left[\begin{array}{c}
\left(N_{\mathrm{BOTH}}+N_{\mathrm{CDS}}\right) \\
-\left(N_{\mathrm{BOTH}}+N_{\mathrm{ASP}}\right)
\end{array}\right]+Q\left(\begin{array}{l}
s_{t-1}^{A} \\
\bar{s}_{t-1}
\end{array}\right)+\left(\begin{array}{c}
u_{t}^{\mathrm{ASP}} \\
u_{t}^{\mathrm{CDS}}
\end{array}\right),
$$

where $\left(u_{t}^{\mathrm{ASP}}, u_{t}^{\mathrm{CDS}}\right)$ is a vector white noise with $E\left(u_{t}\right)=0$ and $\operatorname{Var}\left(u_{t}\right)=\Omega>0$. In $u_{t}$ we include both the common components and the participants' noises. ${ }^{45}$ The model in Equation (15) can be changed into a VECM model by subtracting vector of prices $\left(\left(s_{t}^{A}, \bar{s}_{t}\right)^{\prime}\right.$ from both sides:

$$
\left(\begin{array}{c}
\Delta s_{t}^{A} \\
\Delta \bar{s}_{t}
\end{array}\right)=\frac{H \beta_{3}}{B}\left[\begin{array}{c}
\left(N_{\mathrm{BOTH}}+N_{\mathrm{CDS}}\right) \\
-\left(N_{\mathrm{BOTH}}+N_{\mathrm{ASP}}\right)
\end{array}\right]+(Q-I)\left(\begin{array}{l}
s_{t-1}^{A} \\
\bar{s}_{t-1}
\end{array}\right)+\left(\begin{array}{l}
u_{t}^{\mathrm{ASP}} \\
u_{t}^{\mathrm{CDS}}
\end{array}\right)
$$

with

$$
Q-I=\frac{1}{B}\left[\begin{array}{cc}
-H\left(N_{\mathrm{BOTH}}+N_{\mathrm{CDS}}\right) & H \beta_{2}\left(N_{\mathrm{BOTH}}+N_{\mathrm{CDS}}\right) \\
H\left(N_{\mathrm{BOTH}}+N_{\mathrm{ASP}}\right) & -H \beta_{2}\left(N_{\mathrm{BOTH}}+N_{\mathrm{ASP}}\right)
\end{array}\right] .
$$

The previous expression can be transformed into the following final expression (Equation (15)):

$$
\left(\begin{array}{c}
\Delta s_{t}^{A} \\
\Delta \bar{s}_{t}
\end{array}\right)=\frac{H}{B}\left[\begin{array}{c}
-\left(N_{\mathrm{BOTH}}+N_{\mathrm{CDS}}\right) \\
\left(N_{\mathrm{BOTH}}+N_{\mathrm{ASP}}\right)
\end{array}\right]\left(1,-\beta_{2},-\beta_{3}\right)\left(\begin{array}{c}
s_{t-1}^{A} \\
\bar{s}_{t-1} \\
1
\end{array}\right)+\left(\begin{array}{c}
u_{t}^{\mathrm{ASP}} \\
u_{t}^{\mathrm{CDS}}
\end{array}\right) .
$$

\section{Appendix 2}

In this paper, we adopt GG's methodology and thus, their PT component decomposition to measure market contribution to price discovery. GG PT decomposition has the following form:

$$
X_{t}=A_{1} f_{t}+A_{2} z_{t}
$$


where $f_{t}$ is the permanent component, $z_{t}$ is the transitory component, and $A_{1}$ and $A_{2}$ are loading matrices. The components $f_{t}$ and $z_{t}$ are linear combinations of $X_{t}$ such that $f_{t} \sim I(1), z_{t} \sim I(0), z_{t}$ does not Granger cause $f_{t}$ in the long run and:

$$
\begin{aligned}
& f_{t}=\gamma^{\prime} X_{t} \\
& A_{1}=\beta_{\perp}\left(\alpha_{\perp}^{\prime} \beta_{\perp}\right)^{-1} \text { and } \gamma=\left(\alpha_{\perp}^{\prime} \beta_{\perp}\right)^{-1} \alpha_{\perp}^{\prime},
\end{aligned}
$$

where $\alpha_{\perp}$ and $\beta_{\perp}$ are $2 \times 1$ vectors such that $\alpha_{\perp}^{\prime} \alpha_{\perp}=0$ and $\beta_{\perp}^{\prime} \beta_{\perp}=0$ or equivalently:

$$
\begin{aligned}
& \alpha_{1, \perp}=\frac{H}{B}\left(N_{\mathrm{BOTH}}+N_{\mathrm{ASP}}\right) \\
& \alpha_{2, \perp}=\frac{H}{B}\left(N_{\mathrm{BOTH}}+N_{\mathrm{CDS}}\right),
\end{aligned}
$$

while $\beta_{\perp}=\left(\beta_{2}, 1\right)$. Taking all these things together we have that:

$$
\gamma^{\prime}=\left[\begin{array}{c}
\frac{\left(N_{\mathrm{BOTH}}+N_{\mathrm{ASP}}\right)}{\beta_{2}\left(N_{\mathrm{BOTH}}+N_{\mathrm{ASP}}\right)+\left(N_{\mathrm{BOTH}}+N_{\mathrm{CDS}}\right)}, \\
\frac{\left(N_{\mathrm{BOTH}}+N_{\mathrm{CDS}}\right)}{\beta_{2}\left(N_{\mathrm{BOTH}}+N_{\mathrm{ASP}}\right)+\left(N_{\mathrm{BOTH}}+N_{\mathrm{CDS}}\right)}
\end{array}\right]
$$

and the permanent component $f_{t}$ is defined as:

$$
\frac{\left(N_{\mathrm{BOTH}}+N_{\mathrm{ASP}}\right)}{\beta_{2}\left(N_{\mathrm{BOTH}}+N_{\mathrm{ASP}}\right)+\left(N_{\mathrm{BOTH}}+N_{\mathrm{CDS}}\right)} s_{t}^{A}+\frac{\left(N_{\mathrm{BOTH}}+N_{\mathrm{CDS}}\right)}{\beta_{2}\left(N_{\mathrm{BOTH}}+N_{\mathrm{ASP}}\right)+\left(N_{\mathrm{BOTH}}+N_{\mathrm{CDS}}\right)} \bar{s}_{t},
$$

where the factor that multiplies $s_{t}^{A}$ represents the price discovery measure attributed to the ASP $\left(\mathrm{PD}_{1}\right)$ and the factor that multiplies $\bar{s}_{t}$ represents the price discovery measure attributed to the $\operatorname{CDS}\left(\mathrm{PD}_{2}\right)$. The ratio $\gamma$ in Equation (A8) that is obtained from the orthogonal vector to $\alpha$, which is denoted as $\alpha_{\perp}$ (see Equations (A7a) and (A7b)), can be understood as the relative number of market participants in a given market with respect to the other.

The percentage of price discovery attributable to ASP and CDS markets can also be defined as:

$$
\frac{\mathrm{PD}_{1}}{\mathrm{PD}_{1}+\mathrm{PD}_{2}}=\mathrm{GG}_{1} \text { and } \frac{\mathrm{PD}_{2}}{\mathrm{PD}_{1}+\mathrm{PD}_{2}}=\mathrm{GG}_{2} \text {, }
$$

where $\mathrm{GG}_{1}$ and $\mathrm{GG}_{2}$ represent the GG price discovery metrics for the ASP and the CDS markets, respectively.

These metrics can be defined equivalently as:

$$
\mathrm{GG}_{1}=\frac{\alpha_{2}}{-\alpha_{1}+\alpha_{2}} \text { and } \mathrm{GG}_{2}=\frac{-\alpha_{1}}{-\alpha_{1}+\alpha_{2}}
$$

After substituting we obtain:

$$
\mathrm{GG}_{1}=\frac{N_{\mathrm{BOTH}}+N_{\mathrm{ASP}}}{2 N_{\mathrm{BOTH}}+N_{\mathrm{ASP}}+N_{\mathrm{CDS}}} \quad \text { and } \quad \mathrm{GG}_{2}=\frac{N_{\mathrm{BOTH}}+N_{\mathrm{CDS}}}{2 N_{\mathrm{BOTH}}+N_{\mathrm{ASP}}+N_{\mathrm{CDS}}} .
$$

In order to be consistent with our model we investigate price discovery based on the metrics that when transformed into relative terms are equivalent to the GG approach's metrics of Equation (A10). A cointegrating vector between credit spreads different from $(1,-1)$ can be theoretically supported by our price discovery model given that the standard requirement that $\beta_{2}=1$ may be very restrictive. 